\title{
Large-Scale Preparation of Low-Cost Nonfullerene Acceptors for Stable and Efficient Organic Solar Cells
}

Wenrui Liu, ${ }^{1,2,3}$ Shengjie Xu, ${ }^{1,3}$ Wuyue Liu, ${ }^{1,2}$ Xiaozhang Zhu ${ }^{1,2,4, *}$

${ }^{1}$ Beijing National Laboratory for Molecular Sciences, CAS Key Laboratory of Organic Solids, Institute of Chemistry, Chinese Academy of Sciences, Beijing 100190, China

${ }^{2}$ School of Chemical Sciences, University of Chinese Academy of Sciences, Beijing 100049, China

${ }^{3}$ These authors contributed equally

${ }^{4}$ Lead Contact

*Correspondence: $\underline{x z h u @ \text { iccas.ac.cn }}$ 


\begin{abstract}
Despite the development of nonfullerene acceptors (NFAs) that have made a breakthrough in the photovoltaic performance, large-scale preparation of NFAs that is prerequisite for commercial application has never been explored. Herein, we designed two dodecacyclic all-fused-ring electron acceptors, F11 and F13, and develop a whole set of synthetic procedures, achieving unprecedented scalable preparation of NFAs in the lab at a 10-g scale notably within one day. F11 and F13 display the lowest costs among reported NFAs, even comparable with the classical donor material, P3HT. By matching a medium-bandgap polymer donor, F13 delivers power conversion efficiencies of over $13 \%$, which is an efficiency record for non-INCN acceptors. Benefiting from the intrinsically high stability, OSCs based on F11 and F13 show device stability superior to the typical ITIC- and Y6-based OSCs as evidenced by the tiny burn-in losses. The current work presents a first example for large-scale preparation of low-cost NFAs with good efficiency and high device stability, which is significant for OSC commercialization in near future.
\end{abstract}




\section{Introduction}

Organic solar cells (OSCs) are considered as a promising technique for sustainable energy because of their great potential in low cost, light weight, and large-area processability. ${ }^{1-5}$ As the photovoltaic power generation is intrinsically correlated with the active-layer area, large-scale preparation of the photovoltaic active materials for large-area modules is a rigid demand. It was estimated that a few hundred kilograms of organic materials are needed for a photovoltaic power station to generate $100 \mathrm{MW}$ of electricity under peak illumination conditions. ${ }^{6}$ Unfortunately, to our knowledge, $\mathrm{P} 3 \mathrm{HT}$ is still the only organic photovoltaic material that is commercially available at a $>10 \mathrm{~kg}$ scales up to date. ${ }^{7,8}$

The last few years have witnessed a great breakthrough in the power conversion efficiency (PCE) for OSCs, and this can be attributed to the rapid development of nonfullerene acceptors (NFAs). ${ }^{9-22}$ However, their large-scale preparation is far from being achieved. The huge gap between the laboratory where the preparation of NFAs reported in the literature is at the milligram level, and industry where kilogram-scale preparation of NFAs is required, has become one of the biggest obstacles for OSC commercialization, which, thus, should be of high concern. ITIC, a landmark NFA developed by Zhan, et al., that takes multiple conjugated heteroaromatic rings as the central electron-donating core, 2-(3-oxo-2,3-dihydro- $1 H$-inden-1-ylidene)malononitrile (INCN) as the terminal electron-accepting unit, drew great attention to the design of the current state-of-the-art acceptor-donor-acceptor (A-D-A)-type acceptors. Design strategies such as conjugation expansion, ${ }^{10,23}$ heteroatom incorporation, ${ }^{20,24-29}$ terminal fluorination, ${ }^{30,31}$ and sidechain engineering ${ }^{16,32,33}$ have effectively contributed to the performance promotion, but also led to the increased synthesis complexity and brought a great challenge to the large-scale preparation of NFA materials. Taking Y6 as an example, its synthesis consists of 16 steps when starting from 
commercially available materials, resulting in a low total yield of less than $5 \% .{ }^{34,35}$ Progress in decreasing synthesis complexity of NFAs has been made in the past few years. Li et al. reported two low-cost acceptors MO-IDIC and MO-IDIC-2F, that show a simplified synthetic route of the central fused heteroarenes. ${ }^{36}$ Besides, NFAs with partially or fully unfused backbones, have recently been explored because of their simple molecular struc-tures. ${ }^{35,37-40}$ For example, Li et al. developed several unfused electron acceptors that can be achieved from simple aromatic motifs. Nevertheless, problems still exist including the low yields in synthesis and tedious purification processes. Thus, it is of vital significance to design new NFAs with high scalability and develop convenient synthetic technology for large-scale preparation.

Although INCN-type NFAs have achieved a great breakthrough in PCE, their stability is an important issue in practical applications, for example, the exocyclic double bond is vulnerable to water, oxygen or other nucleophiles. ${ }^{41-46}$ Quite recently, it has been reported that INCN-type NFAs would produce fused-ring isomers involving intramolecular 6-e electrocyclizations in the photodegradation. ${ }^{47}$ To address this issue, our group recently proposed the "all-fused-ring electron acceptor (AFAR)" concept and reported an AFRA (ITYM) ${ }^{48-50}$ that displays intrinsically better chemical, photochemical and thermal stability than those based on INCN-type terminals. However, the one-dimensional stacking of ITYM, the deep occupied molecular orbital (HOMO) of -5.78 $\mathrm{eV}$ and the large optical gap of $1.68 \mathrm{eV}$ with the main absorption located in visible region for ITYM have limited the further performance promotion. Herein, we designed two new AFRAs named as F11 and F13 by introducing a benzothiadiazole-based core (Figure 1). ${ }^{51}$ Compared with ITYM, the HOMO was raised to $-5.64 \mathrm{eV}$ and $-5.65 \mathrm{eV}$ for F11 and F13, respectively, and the optical gaps were decreased to $1.44 \mathrm{eV}$ with the main absorption located in near-infrared region. To address the large-scale preparation of AFRAs, we developed an entire preparation route that 
enables the scalable preparation of F11/F13 at a 10-g level in the lab, notably within one day. The cost analysis indicates that F11 and F13 show the lowest cost among so far reported NFAs and can be comparable with that of P3HT. By matching with D18 polymer donor, PCE of over 13\% for F13 was achieved. Inspiringly, this is the efficiency record among the non-INCN acceptors including fullerene-,${ }^{52-54} \mathrm{PDI}-,{ }^{55-57}$ and rhodanine-type ${ }^{58-60}$ acceptors that also act as a critical role in the development of OSCs. Stability investigations reveal excellent photochemical stability in films of F11 and F13 under ambient conditions compared with the representative NFAs, ITIC, and Y6, which contributes to the superior device stability as evidenced by tiny burn-in losses.

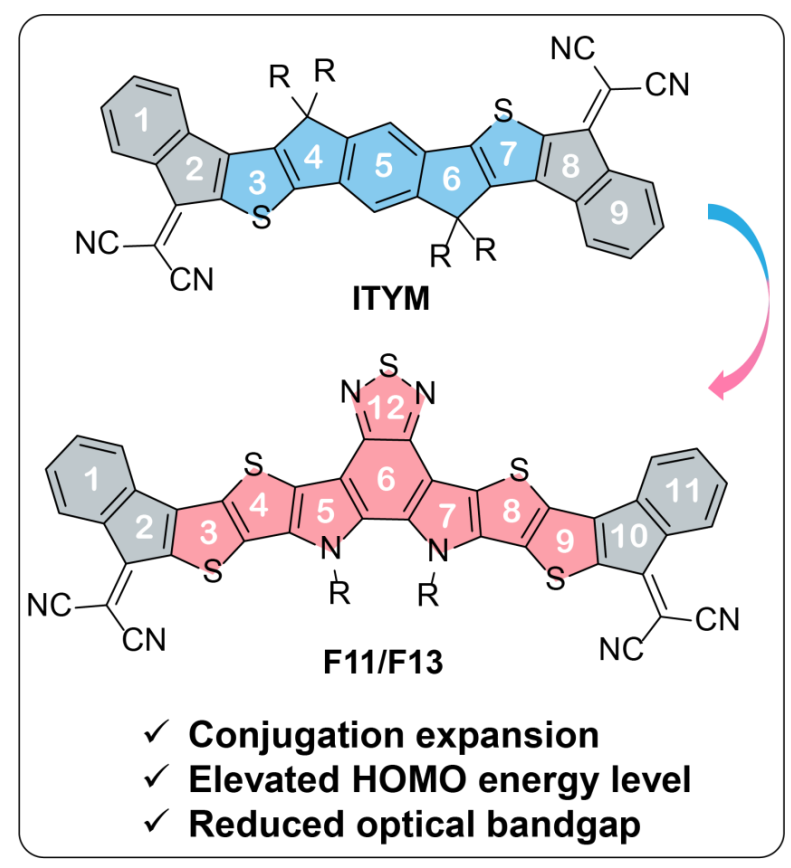

Figure 1 | Design of dodecacyclic AFRAs, F11/F13.

\section{RESULTS and DISCUSSION}

\section{Macroscopic preparation of All-Fused-Ring Electron Acceptors F11 and F13}

Because large-scale preparation requires a whole set of optimized synthetic procedures, not just a certain step, we optimized the synthetic route for F11/F13 and the detailed processes are shown in Figure 2. In the first step, we selected an efficient catalytic system of 
tris(benzylideneacetone)dipalladium and tris(2-methylphenyl)phosphine for the Stille-type crosscoupling reaction, in which the starting materials of 4,7-dibromo-5,6dinitrobenzo[c] $[1,2,5]$ thiadiazole and tributyl(thieno[3,2-b]thiophen-2-yl)stannane are accessible commercially or can be prepared in the lab at a large scale. We took advantage of the solubility difference between the reactants and the product to obtain compound $\mathbf{1}$ by direct filtration. In comparison with the corresponding synthesis in Y6, the reaction time was drastically reduced from $12 \mathrm{~h}$ to $15 \mathrm{~min}$. In the second step of nitrocyclization, we optimized the reaction by replacing triethyl phosphate with more available triphenylphosphine. The $o$-dichlorobenzene solution of compound 1 and triphenylphosphine was heated at $180^{\circ} \mathrm{C}$ for $2 \mathrm{~h}$. High temperature effects the product purification equivalent to recrystallization, and reddish-brown powder of $\mathbf{2}$ was directly obtained by immediate filtration. In the third step of alkylation, the extracted organic layer was passed through a thin-layer diatomite to remove a small amount of excess potassium carbonate. Because this reaction is clean and shows no byproducts, the resulting product $\mathbf{3}$ is directly used for the next step without further purification. For the fourth step of Friedel-Crafts acylation, a dichloromethane solution of compound $\mathbf{3}$ was added dropwise to that of aluminum trichloride and 2-bromobenzoyl chloride. Immediately, a crude product of $\mathbf{4 a}$ was solidified by filtering and washed with methanol, due to a high reaction yield without impurity ensuring that further purification is not necessary. A total yield of $50 \%$ for the presented four steps is achieved. The fifth step involves successive intramolecular cyclization and Knoevenagel condensation. We selected $\mathrm{Pd}$-catalyzed $\mathrm{C}-\mathrm{H}$ activation for intramolecular cyclization in consideration of its great potential for a green, sustainable and atom-efficient synthesis at large scale. ${ }^{61}$ After reacting for $15 \mathrm{~min}$, the crude product was directly used for the next condensation without any purification as a result of the efficient nature of $\mathrm{C}-\mathrm{H}$ activated cyclization. A different reaction from the 
condensation reaction occurred in INCN-type NFAs, and this condensation was completed in an extremely short period of less than five min at room temperature. Finally, the target molecule F11 was purified by recrystallization in dichloromethane/petroleum ether, after passing through diatomite. It is noteworthy that the whole synthetic process eliminates the need for column chromatography that is perfectly manageable at the laboratory scale yet very expensive or even impossible at the industrial scale. ${ }^{7}$ Finally, all these synthetic advantages throughout the whole procedures contributed to the fact that the goal of large-scale preparation of acceptors was achieved, in which over $10 \mathrm{~g}$ of F11 was obtained in the lab and a total yield of $33 \%$ was produced despite a certain waste of products caused by recrystallization, equivalent to over $80 \%$ yield for each step. Moreover, the synthetic process takes an extremely short time, enabling the rapid preparation of NFAs at a large scale within one day, while most NFAs take more than one week.10 The synthetic process of F13 was similar to that of F11, and F11 and F13 are fully characterized by using ${ }^{1} \mathrm{H}-\mathrm{NMR},{ }^{13} \mathrm{C}-\mathrm{NMR}$, MALDI-TOF-MS and elemental analysis. We believe that such a facile and efficient synthetic technique can also be transferred to kg-scale industrial production.

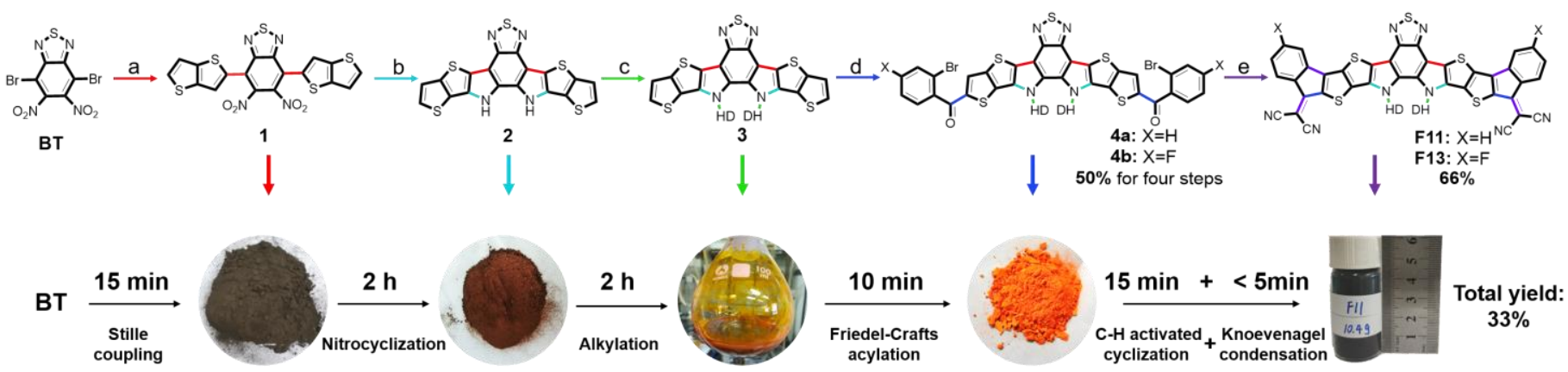

Figure 2. Quick large-scale preparation of the all-fused-ring acceptors, F11 and F13. a, $\mathrm{Pd}_{2}(\mathrm{dba})_{3}, \quad \mathrm{P}(o \text {-tol })_{3}$, tributyl(thieno[3,2-b]thiophen-2-yl)stannane, toluene. $\quad \mathrm{b}, \quad \mathrm{PPh}_{3}, \quad o-$ dichlorobenzene. c, $\mathrm{HD}-\mathrm{Br}, \mathrm{K}_{2} \mathrm{CO}_{3}, N, N$-dimethylformamide, $\mathrm{HD}=2$-hexyldecanyl. d, $\mathrm{AlCl}_{3}, o$ bromoaryl chloride, dichloromethane. e, $1 . \mathrm{K}_{2} \mathrm{CO}_{3}, N, N$-dimethylacetamide, $\mathrm{Pd}(\mathrm{OAc})_{2}, \mathrm{PH}(\mathrm{cyc}$ hex $)_{3} \cdot \mathrm{BF}_{4} ; 2$. Malononitrile, $\mathrm{TiCl}_{4}$, pyridine, chlorobenzene.

\section{Cost analysis}

We analyzed the costs of F11 and F13 based on large-scale preparation. In the case of only 
considering the cost of reagents and solvents used in the whole synthetic procedure, we calculated the lab-scale total costs $\mathrm{C}_{\mathrm{g}}(\$ / \mathrm{g})$ of $\mathrm{F} 11$ and F13 according to actual consumption, and the details are listed in Table S1 (Supporting Information). Compared with the $\mathrm{C}_{\mathrm{g}}$ s reported for other organic photovoltaic materials, ${ }^{36} \mathrm{~F} 11$ and F13 have incredibly low costs, with $\mathrm{C}_{\mathrm{g}}$ of 11.4 \$/g for F11 and 11.5 \$/g for F13, which are much lower than other NFAs and are almost at the same level as P3HT (10.8 \$/g), as illustrated in Figure 3a and Table S2. It should be noted that these cost values will be further reduced if placed on an industrial mass production basis. The extremely low costs of our acceptors are partly because of the simplification of the purification process, especially the absence of column chromatography. According to the statistics, ${ }^{36}$ the costs of purification with column chromatography in most NFAs account for over $30 \%$, even up to $50 \%$ of the total costs, as a result of consuming large amounts of silica gel and solvents. On the other hand, the design and selection of $o$-bromoaryl chloride as terminal units is also an important reason for the cost reduction. From the material suppliers (e.g., Aladdin), o-bromoaryl chloride costs about $3 \$ / g$ based on a 5-g package, which is quite economical compared with $138 \$ / \mathrm{g}$ for INCN and $350 \$ / \mathrm{g}$ for $2 \mathrm{~F}-\mathrm{INCN}$. It should be noted that labor costs that usually are ignored by the academic community accounting for a large percentage of the total cost in actual industrial production. The scalable preparation of F11/F13 could be finished within one day, thus significantly reducing in labor costs. 
A

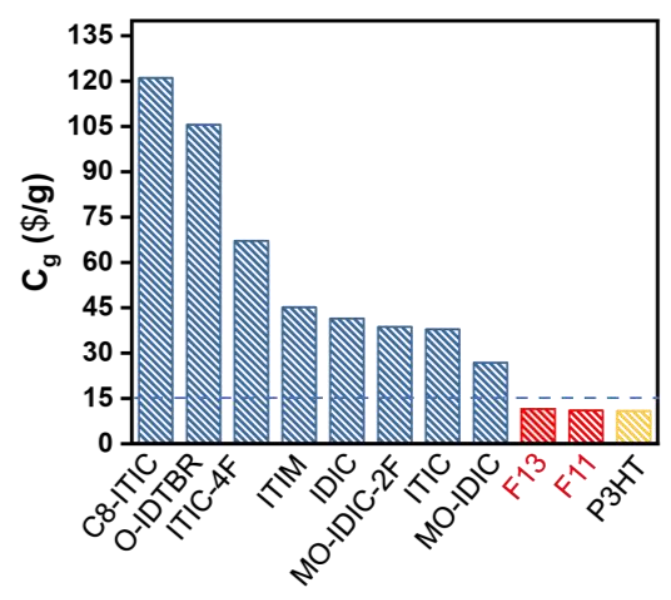

B

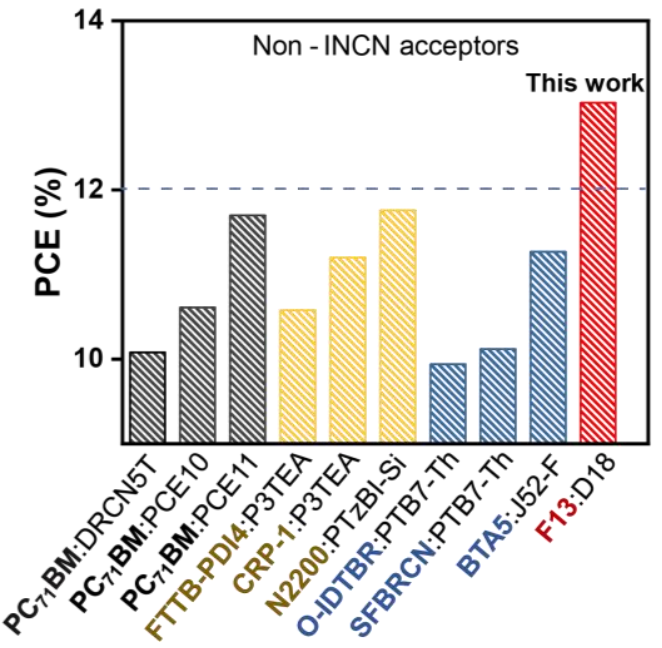

Figure 3. Statistics of costs and PCEs. (A) Histogram of material costs $C_{g}(\$ / g)$ for the different photovoltaic materials (material costs are adopted from the reference, ${ }^{36}$ except for our acceptors). (B) Statistics of high PCEs for typical non-INCN series photovoltaic acceptors (Table S3).

\section{Chemical, photochemical and thermal stability}

It has been found that exocyclic double bonds in acceptors, especially those based on INCN series terminals, are one of the most important triggers of material instability. Our previous work also confirms that avoiding such highly polarized and isolated double bonds facilitates the stability of the material. Herein, the chemical and photochemical stability of F11 and F13 are examined and two typical acceptors based on the INCN-group, ITIC and Y6, are chosen for comparison. Chemical stability measurements were performed by monitoring the absorption spectra of four acceptors before and after being treated with ethanolamine (EA) in the corresponding THF solutions as shown in Figure S1, and Figure 4a depicts the time-dependent absorption decays of acceptors at the corresponding maximum absorptions. Immediately after the addition of EA (100 equiv.), a significant color change (Figure S3a) and decay of absorption occurred in Y6 and ITIC solutions. It is shown that almost no attenuation of the maximum absorption peak intensity of F11 and F13 was found, even $12 \mathrm{~h}$ after adding EA. However, obviously decreased intensities of $83 \%$ and more than $99 \%$ for Y6 and ITIC, respectively, were observed, and meanwhile, the absorption 
at 350-500 $\mathrm{nm}$ increased to a different extent, which can be attributed to interruption of the D-A conjugation.

Photostability of photovoltaic-active materials under ambient conditions plays an important role in OSCs. Thus, we investigated the photochemical stability of the four acceptors (F11, F13, ITIC and Y6) for comparison, and Figure S2 displays the evolution of absorption spectra in THF solutions and in films with irradiation time. After irradiating for 10 min under AM $1.5 \mathrm{G}$ at 100 $\mathrm{mW} \mathrm{cm} \mathrm{cm}^{-2}$, the absorption peak of air-saturated ITIC solution in the 600-700 $\mathrm{nm}$ range has disappeared, suggesting the $\mathrm{D}-\mathrm{A}$ conjugation was broken. The maximum absorption peak intensity of Y 6 remains $41 \%$ of the original value after 80 min, while over $60 \%$ for F11 and F13. They all exhibited higher photostability in films than in solutions, as a result of stronger molecular interaction in films restricting the conformational change and diffusion of water and oxygen. To accelerate the rate of aging, we chose a stronger irradiation intensity of $300 \mathrm{~mW} \mathrm{~cm}^{-2}$ (LED) in air. In addition, the change of normalized UV-Vis maximum absorptions from D-A conjugation is depicted in Figure $4 \mathrm{~b}$. The intensity of the maximum absorption peaks decayed $75 \%$ for Y 6 and only $37 \%$ and $34 \%$ for F11 and F13, respectively, after 207-h illumination. Apparently, within 2 $\mathrm{h}$, the absorption of ITIC film is completely bleached and so was the color (Figure S3b). The photooxidation behavior of NFAs corresponds to molecular chain bond scission due to the vulnerable carbon-carbon double bonds. ${ }^{44}$ Besides, the degradation can partly be attributed to the reduced transition oscillator strength between HOMO-LUMO wavefunctions, because of a twist about the D-A dihedral angle upon continuous irradiation ${ }^{62}$ thus resulting in eventual bond breakage and intramolecular 6-e electrocyclizations, ${ }^{47}$ which is absent for the all-fused-ring molecular frame-work in F11 and F13. As a result, F11 and F13 exhibit excellent photostability. By fitting the decay curves, whereas the half-life of Y6 is $162 \mathrm{~h}$, that of our materials is over 300 
$\mathrm{h}$, which is almost twice as stable as Y6.

The thermal stress is also a predominant acceleration factor for degradation and the thermostability was determined using thermogravimetric analysis (TGA). F11 and F13 had higher decomposition temperatures $\left(\mathrm{T}_{\mathrm{d}}\right)$ at $5 \mathrm{wt} \%$ of up to $376^{\circ} \mathrm{C}$ and $377^{\circ} \mathrm{C}$, respectively, than $318^{\circ} \mathrm{C}$ for Y6 and $345^{\circ} \mathrm{C}$ for ITIC, even among the reported INCN-type NFAs, which are illustrated in Figure S4. The low thermal stability of INCN-based ITIC and Y6 can be attributed to highly polarized single bonds be-tween the electron-rich cores and electron-deficient terminals, while that does not exist in F11 and F13.

A

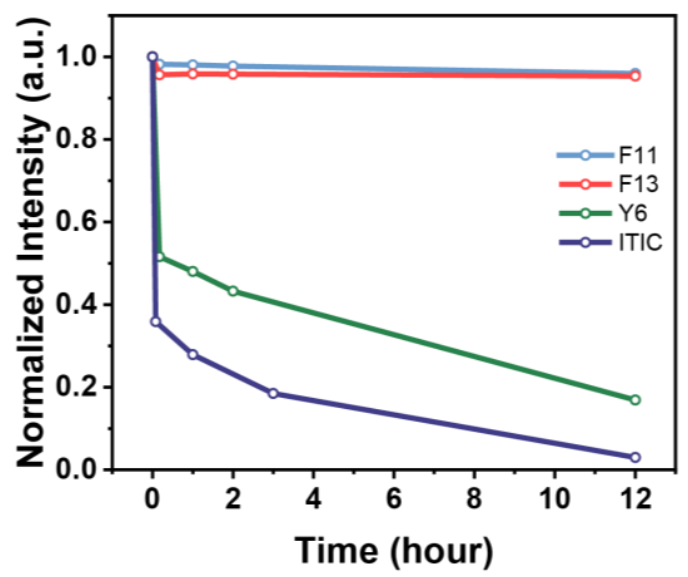

B

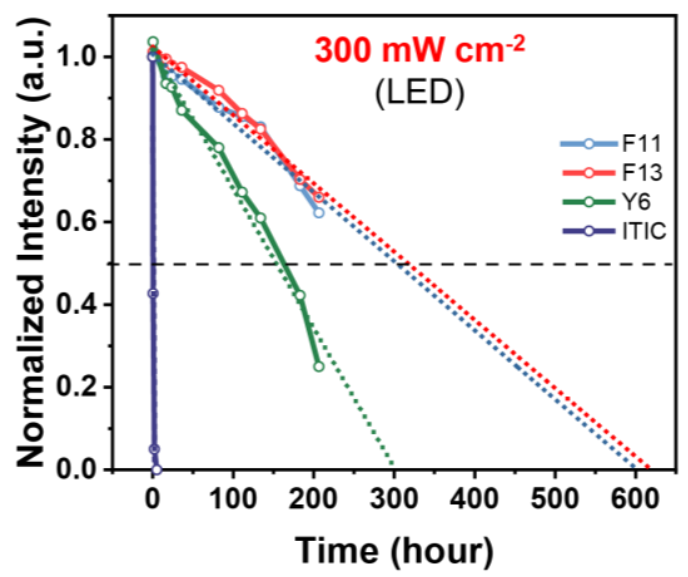

Figure 4. Stabilities of four NFA acceptors. The time-dependent absorption decays of acceptors at the corresponding maximum absorptions upon (A) the EA treatment in THF: $\mathrm{H}_{2} \mathrm{O}$ mixtures $(96: 4, \mathrm{v} / \mathrm{v})$ (the concentration of NFAs is controlled at $10^{-5} \mathrm{M}$, while that of EA is $10^{-3} \mathrm{M}$ ) and (B) $300 \mathrm{~mW} \mathrm{~cm}^{-2}$ (LED) irradiation in films.

\section{Photo- and electrochemical properties}

Figure 5a shows the normalized absorptions of F11 and F13 in solution and film. The maximum absorption peaks of F11 are $717 \mathrm{~nm}$ and $773 \mathrm{~nm}$ in solution and film, respectively, which are extremely close to those of F13. Compared with the absorption spectra in solution, the maximum absorption peaks in films are redshifted by $56 \mathrm{~nm}$, because of the stronger intermolecular $\pi-\pi$ interactions. The optical bandgaps are both $1.44 \mathrm{eV}$ for F11 and F13. The 
frontier orbital energy levels of F11 and F13 were calculated by cyclic voltammetry (Figure S5 and Figure 5b). In comparation with ITYM, the elevated highest occupied molecular orbital (HOMO) of F11 and F13 are -5.64 and $-5.65 \mathrm{eV}$, respectively, and the lowest unoccupied molecular orbital (LUMO) energy levels are -3.78 and $-3.81 \mathrm{eV}$ for F11 and F13, respectively. The deeper energy levels of F13 than F11 especially the LUMO, are ascribed to the electronwithdrawing ability of the $\mathrm{F}$ atom. The suitable optical bandgaps and the well-aligned energy levels formed by D18 and F11/F13 indicate that these materials can be used for OSC fabrication.

\section{Photovoltaic performance}

To investigate the photovoltaic performance of F11 and F13, we fabricated the conventional device structure of ITO/PEDOT:PSS/active layer/PDINN/Ag, in which D18 was selected as the donor. Thermal annealing (TA) temperatures and the ratios of donor/acceptor were carefully optimized, and the details are summarized in Supporting Information. As shown in Figure 5c and Table 1, based on the donor/acceptor ratio of 1:1.4 and TA temperatures of $90{ }^{\circ} \mathrm{C}, \mathrm{F} 11 / \mathrm{D} 18$-based OSCs give the best PCE of $11.20 \%$, with the open-circuit voltage $\left(V_{\mathrm{oc}}\right)$ of $0.885 \pm 0.005 \mathrm{eV}$, shortcircuit current density $\left(J_{\mathrm{sc}}\right)$ of $19.15 \pm 0.68 \mathrm{~mA} \mathrm{~cm}^{-2}$ and fill factor (FF) of $65.08 \pm 0.28 \%$, while OSCs based on F13/D18 showed a higher PCE of $13.01 \%$, with the $V_{\mathrm{oc}}$ of $0.822 \pm 0.004 \mathrm{~V}, J_{\mathrm{sc}}$ of $22.26 \pm 0.14 \mathrm{~mA} \mathrm{~cm}-2$ and FF of $70.13 \pm 0.34 \%$, which is the efficiency record for non-INCN NFAs (Figure 3b). The external quantum efficiency (EQE) spectra are revealed in Figure 5d, and show a photo response from roughly 300 to $870 \mathrm{~nm}$ that is in consistence with the absorption of F11 and F13. A stronger and broader photoresponse appears in the devices of F13:D18, i.e., over 70\% of EQEs with a peak value of $80 \%$ at $575 \mathrm{~nm}$ in the broad range of $450-800 \mathrm{~nm}$, than that of F11/D18-based OSCs, thus resulting in the higher integrated $J_{\mathrm{sc}}, 21.72 \mathrm{~mA} \mathrm{~cm}^{-2} \mathrm{vs} 18.99 \mathrm{~mA} \mathrm{~cm}^{-}$

${ }^{2}$. Both these integrated $J_{\mathrm{sc}} \mathrm{S}$ calculated from EQE spectra are consistent with the $J_{\mathrm{sc}} \mathrm{S}$ obtained from 
$J-V$ curves within a $3 \%$ error.

The photocurrent density $\left(J_{\mathrm{ph}}\right)$ versus the effective voltage $\left(V_{\text {eff }}\right)$ was measured to explore the efficiency of charge genera-tion and extraction $\left(J_{\mathrm{ph}}=J_{\mathrm{L}}-J_{\mathrm{D}}\right.$, where $J_{\mathrm{L}}$ and $J_{\mathrm{D}}$ are the current densities under illumination and in the dark, respectively. $V_{\text {eff }}=V_{0}-V_{\text {apply, }}$, where $V_{0}$ is the voltage when $\left(J_{\mathrm{ph}}=0\right.$ and $V_{\text {apply }}$ is the applied external bias voltage). As depicted in Figure 6a, the $J_{\mathrm{ph}}$ reach saturation for $V_{\text {eff }}$ at $2 \mathrm{~V}$, indicating the saturation currents $\left(J_{\text {sat }}\right)$ of F11- and F13-based photovoltaic devices are 20.02 and $22.68 \mathrm{~mA} \mathrm{~cm}^{-2}$, respectively. The charge dissociation probability is defined as $P_{\text {diss }}=J_{\mathrm{ph}} / J_{\text {sat }}$ with the value of $94.7 \%$ for F11-based OSC and $97.8 \%$ for F13-based OSC, revealing the better exciton dissociation in F13:D18-based OSC and thus leading to higher FF. The correlation between $J_{\text {sc }}$ and the light intensity (P) was also studied to examine the charge recombination in Figure $\mathrm{S} 6 \mathrm{~b}$, which follows such an equation relationship: $J_{\mathrm{sc}} \propto P^{\alpha}$, where $\alpha$ is close to 1 suggesting a more negligible bimolecular recombination. The $\alpha$ value of the F13-based device is 0.930 , higher than 0.926 of F11 based device, meaning there is suppressed bimolecular recombination in the F13-based device and these results are in agreement with their FFs. We further investigated the charge transport property by implementing the space-charge limited current (SCLC) method based on holes only (ITO/PEDOT:PSS/active layer/Au) and electrons only (ITO/ZnO/active layer/PFN-Br/Ag) devices. The corresponding experimental data are illustrated in Figure S6 and outlined in Table 1. F13:D18 blends show higher electron mobility of $6.45 \times 10^{-4} \mathrm{~cm}^{-2} \mathrm{~V}^{-1} \mathrm{~s}^{-1}$ than $3.75 \times 10^{-4} \mathrm{~cm}^{-2} \mathrm{~V}^{-1} \mathrm{~s}^{-1}$ of F11:D18 blends. ${ }^{30,31}$ The higher charge mobilities and more balanced $\mu_{\mathrm{h}} / \mu_{\mathrm{e}}$ in F13:D18 blends are beneficial for charge extraction and collection with reduced bimolecular recombination, leading to a promoted $J_{\mathrm{sc}}$ and FF while the electron mobilities of both blends are greater than that of ITYM-blend, $1.27 \times 10^{-4} \mathrm{~cm}^{-2} \mathrm{~V}^{-1} \mathrm{~s}^{-1}$. 
A

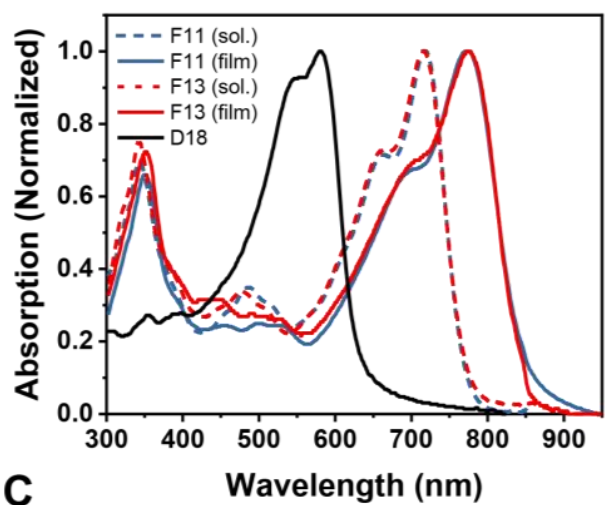

C

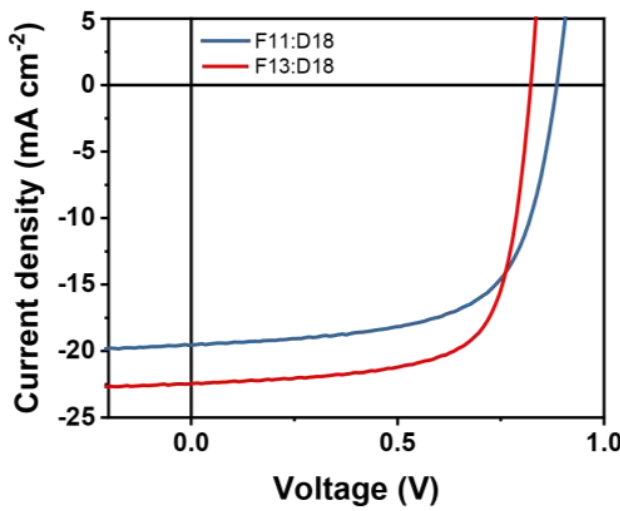

B

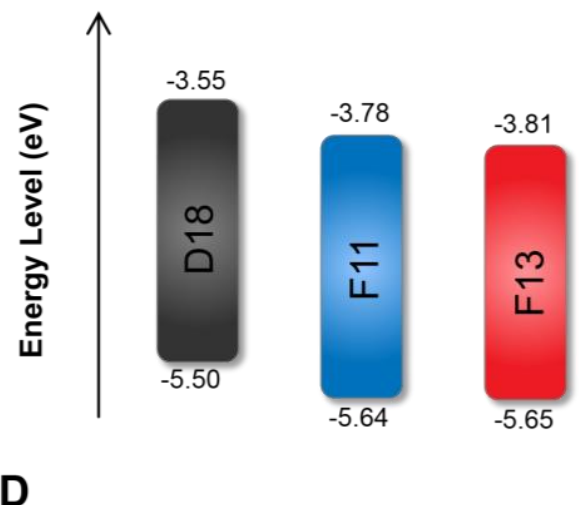

Figure 5. Photovoltaic performance of F11/F13:D18-based OSCs. (A) Normalized UV-visNIR absorption spectra. (B) Energy diagram of D18, F11 and F13. (C) $J-V$ and (D) EQE curves for OSCs based on F11:D18 and F13:D18 under AM 1.5G irradiation $\left(100 \mathrm{~mW} \mathrm{~cm}^{-2}\right)$.

Table 1. Photovoltaic parameters of F11/F13-based OSCs under the illumination of AM 1.5G, $100 \mathrm{~mW} \mathrm{~cm}^{-2}$.

\begin{tabular}{|c|c|c|c|c|c|c|c|c|}
\hline Acceptors & $\begin{array}{l}V_{\text {oc }} \\
(\mathrm{V})\end{array}$ & 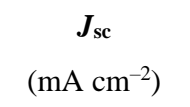 & $\begin{array}{c}\boldsymbol{J}_{\text {cal }} \\
\left(\mathrm{mA} \mathrm{cm}^{-2}\right)\end{array}$ & $\begin{array}{l}\mathbf{F F} \\
(\%)\end{array}$ & $\begin{array}{c}\text { PCE } \\
(\%)\end{array}$ & $\begin{array}{c}\boldsymbol{\mu} \mathbf{h} \\
\left(\times 10^{-4} \mathrm{~cm}^{2} \mathrm{~V}^{-1} \mathrm{~s}^{-1}\right)\end{array}$ & $\begin{array}{c}\boldsymbol{\mu} \mathbf{e} \\
\left(\times 10^{-4} \mathrm{~cm}^{2} \mathrm{~V}^{-1} \mathrm{~s}^{-1}\right)\end{array}$ & $\mu_{\mathrm{e}} / \mu_{\mathrm{h}}$ \\
\hline
\end{tabular}

The average values with standard deviations were obtained from more than 10 individual devices.

\section{Morphology characterization}

The morphologies of active layers were characterized by atomic force microscopy (AFM) and transmission electron micros-copy (TEM). As seen in Figure S7, both blend films have fiberlike morphology to a different extent, while the F13:D18 blend film featured a more uniform film 
surface with a smaller square root mean (RMS) value of $0.873 \mathrm{~nm}$. For TEM images, the F13based film reveals better miscibility between the donor and acceptor, which is favorable for exciton dissociation and charge generation at D/A interface. Grazing incidence wide-angle X-ray scattering (GIWAXS) was performed to further understand the crystallinity and orientation in the neat films and blend films. 2D GIWAXS images and 1D profiles in the in-plane (IP) and out-ofplane (OOP) direction of different films are shown in Figure 6. The neat films of F11 and F13 exhibit strong (010) diffraction peak in the OOP direction at $1.77 \AA^{-1}$ and $1.78 \AA^{-1}$, respectively, indicating a predominant face-on orientation. Also, lamellar stacking in IP direction can be seen in both neat films, and especially for the F13 film, there are two small sharp peaks at $0.29 \AA^{-1}$ and $0.43 \AA^{-1}$. The crystal coherence lengths (CCLs) for $(010)$ diffractions calculated from the Scherrer equation are $1.87 \mathrm{~nm}$ and $2.46 \mathrm{~nm}$ for F11 and F13, respectively, meaning higher crystallinity of F13 film that might be induced by the F atom. In two blend films, there are obvious $(010) \pi-\pi$ stacking in OOP that mainly originated from the acceptor, which is favorable for charge transport in the vertical direction. Similar to the neat films, F13-based blend film possesses a larger CCL of $2.06 \mathrm{~nm}$ in the OOP di-rection than $2.00 \mathrm{~nm}$ in F11-based blend film, which is beneficial for charge transport.

A
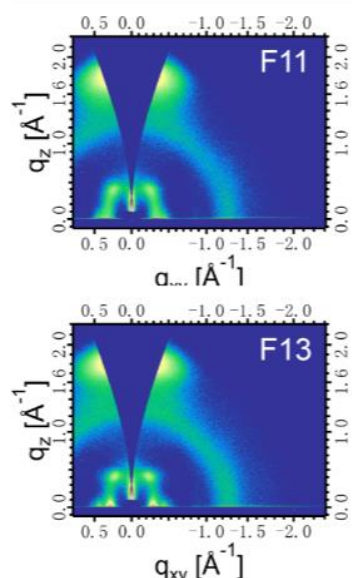

$q_{\mathrm{xy}}\left[\AA^{-1}\right]$
B
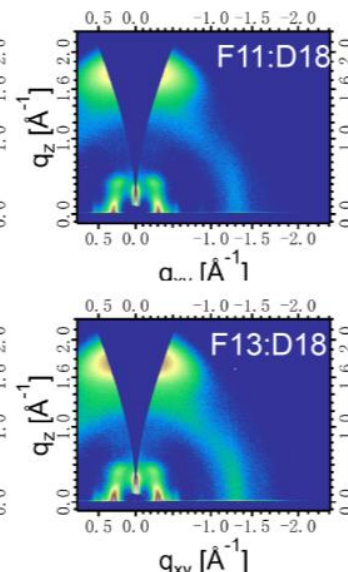

C

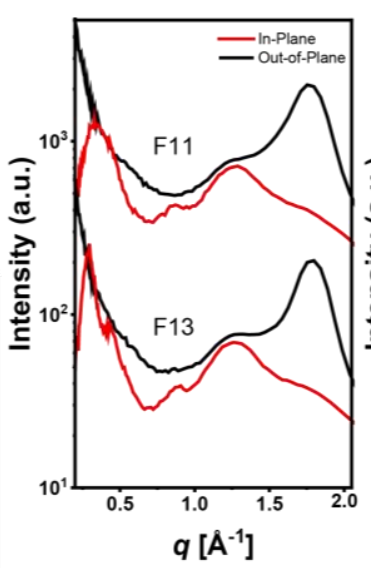

D

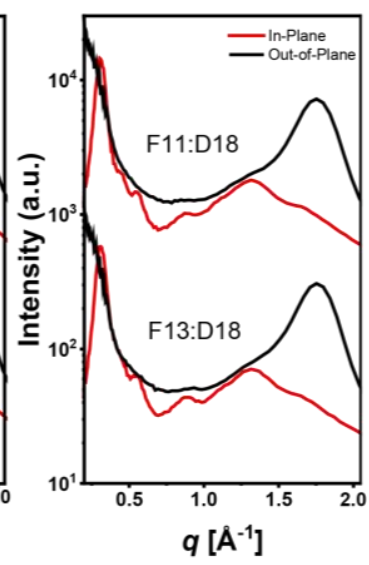

Figure 6. GIWAXS patterns of F11/F13-based active layers. 2D GIWAXS patterns of (A) 
pristine films and (B) blend films. GIWAXS intensity profiles along the in-plane and out-of-plane directions of (C) pristine films and (D) blend films.

\section{Device stability}

The stability of OSCs is the key towards commercial applications, which is closely related to the stability of the active layer materials. Thus, we investigated the photostability of OSCs based on air-processed active layer ${ }^{63-67}$ and compared them with the typical NFA OSCs based on ITIC and Y6. Figure 7 shows the corresponding evolution for normalized photovoltaic parameters (PCE, $V_{\mathrm{oc}}, J_{\mathrm{sc}}$ and FF) upon time and these devices with a configuration of ITO/PEDOT:PSS/active layer/PDINN/Ag, of which active layers were spin-coated in air, were placed in a glovebox filled with dry nitrogen atmosphere under continuous irradiation (LED, 100 $\mathrm{mW} \mathrm{cm}{ }^{-2}$ ) at $30 \pm 5^{\circ} \mathrm{C}$. During the first $15 \mathrm{~h}$, Y6- and ITIC-based OSCs showed rapid decay of $20 \%$ and $36 \%$, respectively, which is typically referred to burn-in loss, a common phenomenon for most organic solar cells. ${ }^{68,69}$ Benefiting from the high photostability especially in the presence of oxygen and water, the OSCs based on F11 and F13 acceptors exhibited tiny burn-in losses (about $8 \%$ reduction in PCE), which further boosts the long-term stability with a minor decrease in $V_{\mathrm{oc}}, J_{\mathrm{sc}}$ and FF. The PCE of ITIC-based devices decayed much faster, duo to a drop in $J_{\mathrm{sc}}$ and FF. For Y6-based OSCs, the decrease in PCE was mainly attributed to the moderate decrease in Voc. Compared with the $\mathrm{T}_{80}(80 \%$ of the original PCE values) of $1 \mathrm{~h}$ for ITIC-based OSCs and 17 $\mathrm{h}$ for Y6-based OSCs, a longer $\mathrm{T}_{80}$ of $150 \mathrm{~h}$ for F13-based OSCs and $105 \mathrm{~h}$ for F11-based OSCs were estimated. These merits enable OSCs based on F11 and F13 to be suitable for the desirable high-throughput OSC fabrication in air. ${ }^{63,64}$ These results indicate the importance of developing new NFAs with high intrinsic stability in terms of their advantages such as high tolerance to device processing conditions, suitability for high throughput fabrication, excellent long-term device 
stability and reduced costs.

A

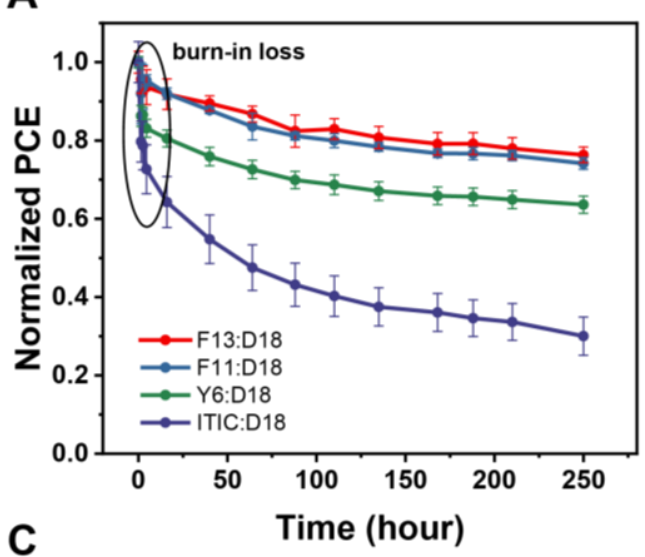

C

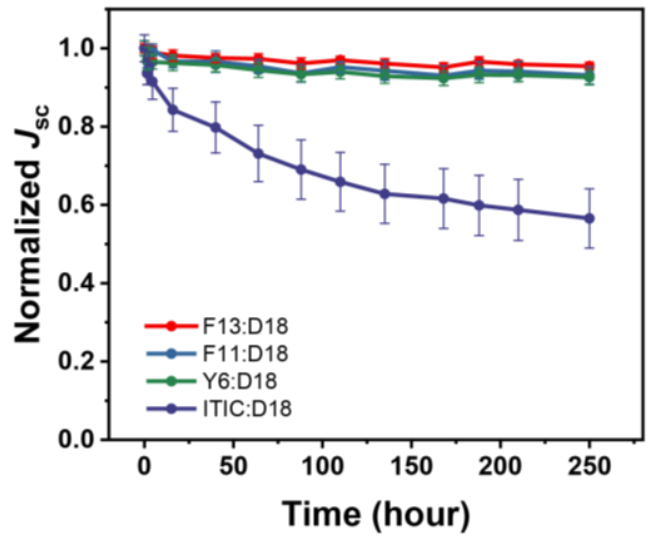

B

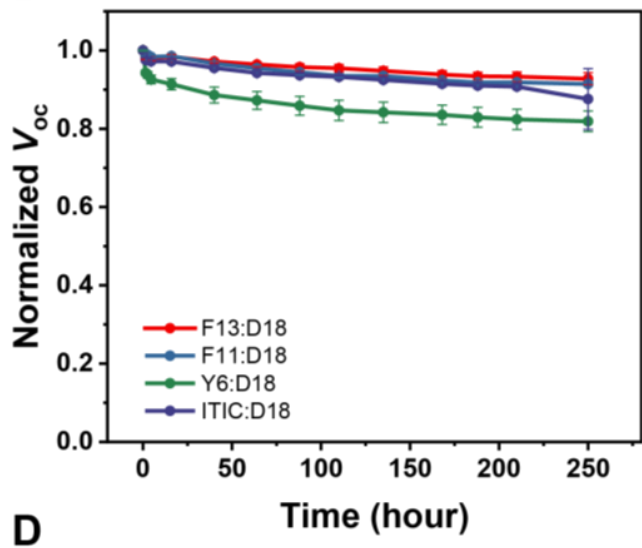

D

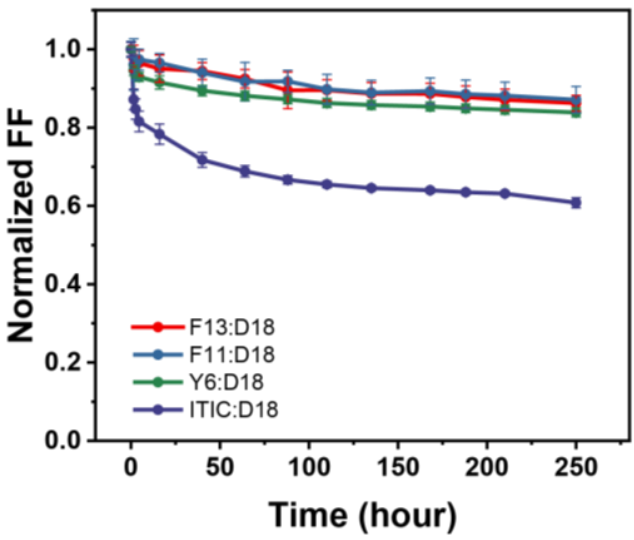

Figure 7. OSC device stability Evolution of (A) PCE, (B) $V_{\mathrm{oc}},(\mathrm{C}) J_{\mathrm{sc}}$ and (D) FF of devices based on air-processed active layers. These devices with structure of ITO/PEDOT:PSS/active layer/PDINN/Ag, were placed in a glovebox filled with dry nitrogen atmosphere under continuous irradiation (LED, $100 \mathrm{~mW} \mathrm{~cm}^{-2}$, an average of six devices).

\section{Discussion}

Based on the all-fused-ring strategy, we designed two new NFAs, F11 and F13, by introducing a $\pi$-extended benzothiadi-azole-based core. To prepare these dodecacyclic NFAs at a large scale, we developed a whole set of synthetic procedures including optimization of catalytic systems such as adopting effective $\mathrm{C}-\mathrm{H}$ activation reaction and simplification of purification operations such as exploiting solubility differences between the starting materials and the corresponding products, all of which leads to the unprecedented scalable preparation of NFAs in the lab at the $10-\mathrm{g}$ level within one day, notably. Both F11 and F13 show low material and labor cost, which are lowest among reported NFAs, and even can be comparable with that of P3HT, the only organic 
photovoltaic material that is low-cost and commercially available in a $10-\mathrm{kg}$ scale. Material stability investigations reveal that the films of F11 and F13 have excellent photochemical stability when exposed to air in comparison with the classical ITIC and Y6 acceptors. The near-infrared absorption, elevated HOMO energy level and much improved electron-transport property for F11 and F13 as compared with ITYM, show their great potential in achieving high-performance OSCs. By matching D18, over 13\% PCE has been realized for F13, which not only is much higher than that of ITYM-based OSCs, 9.51\%, but also is the efficiency record among non-INCN acceptors. Furthermore, F11- and F13-based OSCs exhibit superior photostability, as illustrated by the significantly reduced burn-in losses as compared with ITIC- and Y6-based OSCs, which benefits from the intrinsic high stability of AFRAs. To sum up, we presented in this work a first and successful example for large-scale preparation of low-cost NFAs for stable and efficient devices, which is fundamentally important for OSC commercialization in near future.

\section{Methods}

Materials and synthesis. 4,7-dibroMo-5,6-dinitrobenzo[c] $[1,2,5]$ thiadiazole (yield: 74\%) and tributyl(thieno[3,2- $b]$ thiophen-2-yl)stannane are synthesized by reported methods ${ }^{37}$. Unless stated otherwise, starting materials were obtained from Adamas, Aldrich, J\&K, Alfa Aesar, etc. and were used without further purification. Anhydrous THF and toluene were distilled over $\mathrm{Na} /$ benzophenone prior to use. Anhydrous DMF was purchased form J\&K

Synthesis of compound 1. 4,7-dibromo-5,6-dinitrobenzo[c][1,2,5]thiadiazole (10.2 g, $26.6 \mathrm{mmol})$ and tributyl(thieno[3,2-b]thiophen-2-yl)stannane $(56.5 \mathrm{mmol})$ were dissolved in toluene $(60 \mathrm{~mL})$ in nitrogen atmosphere. Then tris(dibenzylideneacetone)dipalladium (469 mg, $0.5 \mathrm{mmol}$ ) and tris(2-methylphenyl)phosphine $(622 \mathrm{mg}, 2.0 \mathrm{mmol})$ were added in the above mixture. The reaction solution was heated at $90{ }^{\circ} \mathrm{C}$ for 15 minutes and then toluene was removed under reduced 
pressure. The residue was filtered by methane and washed with dichloromethane to get $10.7 \mathrm{~g}$ black crude product.

Synthesis of compound 2. Compound $1(10.7 \mathrm{~g}, 21.3 \mathrm{mmol})$ and triphenylphosphine $(44.5 \mathrm{~g}, 170$ mmol) were dissolved in 1,2-dichlorobenzene $(70 \mathrm{~mL})$. The reaction mixture was purged with nitrogen for 2 minutes and then was heated at $180^{\circ} \mathrm{C}$ for $2 \mathrm{~h}$. Then reddish-brown powder $(6.7 \mathrm{~g})$ was obtained by immediate thermal filtration and washed with dichloromethane.

Synthesis of compound 3. The crude product $2(6.7 \mathrm{~g}, 15.3 \mathrm{mmol})$, potassium carbonate $(31.2 \mathrm{~g}$, $226.1 \mathrm{mmol})$, potassium iodide $(125 \mathrm{mg}, 0.75 \mathrm{mmol})$ and 1-bromo-2-hexyldecane $(14 \mathrm{~g}, 45.9$ mmol) in DMF (50 ml) solvent was heated to $140{ }^{\circ} \mathrm{C}$ for $2 \mathrm{~h}$. The reaction solution was extracted with ethyl acetate. The organic layer was washed with water and brine, and was dried over $\mathrm{MgSO}_{4}$. The solvent and redundant 1-bromo-2-hexyldecane was removed by distillation under reduced pressure. The rest mixture in dichloromethane solvent went through diatomite layer to get almost pure orange liquid (12.4 g). ${ }^{1} \mathrm{H}$ NMR $\left(400 \mathrm{MHz}, \mathrm{CDCl}_{3}\right): \delta 7.42(\mathrm{~m}, 4 \mathrm{H}), 4.63\left(\mathrm{~d},{ }^{3} J=7.6 \mathrm{~Hz}\right.$, 4H), $2.06(\mathrm{~m}, 2 \mathrm{H}), 1.18-0.68(\mathrm{~m}, 60 \mathrm{H}) ;{ }^{13} \mathrm{C} \mathrm{NMR}\left(100 \mathrm{MHz}, \mathrm{CDCl}_{3}\right): \delta 147.7,141.7,136.7,131.9$, $124.7,124.3,123.7,121.4,111.6,54.9,38.7,31.8,31.6,30.4,29.7,29.4,29.1,25.5,25.5,22.6$, $22.5,14.1,14.0$.

Synthesis of compound 4a. 2-Bromobenzoyl chloride (7.74 g, $35.2 \mathrm{mmol}$ ) and aluminum chloride $(9.3 \mathrm{~g}, 70.5 \mathrm{mmol})$ were dissolved in dichloromethane $(70 \mathrm{~mL})$. Then compound 3 (12.4 $\mathrm{g}, 14.0 \mathrm{mmol}$ ) in dichloromethane was added dropwise into the above solution for $10 \mathrm{~min}$. Immediately, the solution was quenched with ice water. The organic layer was washed with water and brine, and was dried over $\mathrm{MgSO}_{4}$. The rest mixture went through diatomite layer and then the product was solidified by filtered with methanol. (16.6 g, 50\% for four steps). ${ }^{1} \mathrm{H}$ NMR (400 MHz, $\left.\mathrm{CDCl}_{3}\right): \delta 7.72\left(\mathrm{~d},{ }^{3} J=8.0 \mathrm{~Hz}, 2 \mathrm{H}\right), 7.68(\mathrm{~s}, 2 \mathrm{H}), 7.53\left(\mathrm{dd},{ }^{3} J=7.2 \mathrm{~Hz},{ }^{4} J=2.0 \mathrm{~Hz}, 2 \mathrm{H}\right), 7.48(\mathrm{t}$, 
$\left.{ }^{3} J=7.2 \mathrm{~Hz}, 2 \mathrm{H}\right), 7.41\left(\mathrm{t},{ }^{3} J=7.6 \mathrm{~Hz}, 2 \mathrm{H}\right), 4.67\left(\mathrm{~d},{ }^{3} J=8.0 \mathrm{~Hz}, 4 \mathrm{H}\right), 2.07(\mathrm{~m}, 2 \mathrm{H}), 1.18-0.68(\mathrm{~m}$, $60 \mathrm{H}) ;{ }^{13} \mathrm{C}$ NMR $\left(100 \mathrm{MHz}, \mathrm{CDCl}_{3}\right): \delta 187.8,147.5,142.6,141.6,140.2,136.8,133.6,133.1$, $131.5,131.5,130.5,128.9,128.4,127.3,119.7,112.6,55.3,38.9,31.7,31.5,30.4,29.7,29.3$, $29.3,29.12,25.5,25.4,22.6,22.5,14.1,13.9$.

Synthesis of compound $\mathbf{4 b}$. The synthetic route is similar to that of compound $\mathbf{4 a}(51 \%$ for four steps). ${ }^{1} \mathrm{H}$ NMR (400 MHz, $\left.\mathrm{CDCl}_{3}\right): \delta 7.69(\mathrm{~s}, 2 \mathrm{H}), 7.55\left(\mathrm{dd},{ }^{3} J=8.4 \mathrm{~Hz},{ }^{4} J=5.6 \mathrm{~Hz}, 2 \mathrm{H}\right), 7.48$ $\left(\mathrm{dd},{ }^{3} J=8.4 \mathrm{~Hz},{ }^{4} J=2.4 \mathrm{~Hz}, 2 \mathrm{H}\right), 7.20\left(\mathrm{td},{ }^{3} J=8.0 \mathrm{~Hz},{ }^{4} J=2.4 \mathrm{~Hz}, 2 \mathrm{H}\right), 4.67\left(\mathrm{~d},{ }^{3} J=8.0 \mathrm{~Hz}\right.$, 4H), 2.06 (m, 2H), 1.18-0.68 (m, 60H); ${ }^{13} \mathrm{C} \mathrm{NMR}$ (100 MHz, $\left.\mathrm{CDCl}_{3}\right): \delta 186.8,164.5,161.9,147.5$, $142.4,141.7,136.7,136.4,136.4,133.1,131.6,130.5,130.5,130.4,128.6,121.2,121.0,120.8$, $120.7,114.8,114.6,112.6,55.3,39.0,31.7,31.5,30.4,29.7,29.3,29.3,29.1,25.5,25.4,22.6$, $22.5,14.1,14.0$.

Synthesis of compound F11. To a solution of compound $4 \mathrm{a}(16.6 \mathrm{~g}, 13.2 \mathrm{mmol})$ in $\mathrm{N}, \mathrm{N}$ dimethylacetamide $(50 \mathrm{ml})$ was added palladium (II) acetate (286 mg, $1.3 \mathrm{mmol})$, tricyclohexylphosphonium tetrafluoroborate $(938 \mathrm{mg}, 2.5 \mathrm{mmol})$ and potassium carbonate $(5 \mathrm{~g}$, $36.2 \mathrm{mmol}$ ) in nitrogen atmosphere and then was heated at $180^{\circ} \mathrm{C}$ for $15 \mathrm{~min}$. Then the mixture was poured into water and filtered, and solid was washed with water and methane, which was directly used for the next step. Pyridine $(4 \mathrm{ml})$ and titanium tetrachloride $(6 \mathrm{ml})$ were added to a mixture of crude product and malononitrile $(3.9 \mathrm{~g}, 59.4 \mathrm{mmol})$ in chlorobenzene $(50 \mathrm{ml})$. Within five minutes, the solution was extracted with dichloromethane $(80 \mathrm{ml})$ and water. The solvent was removed under reduced pressure. The residue in dichloromethane solvent went through a fast filtration with diatomite and then was purified with recrystallization (petroleum ether: dichloromethane $=4: 1 \mathrm{v} / \mathrm{v})$ to give the target molecule $(10.4 \mathrm{~g}, 66 \%) .{ }^{1} \mathrm{H} \mathrm{NMR}\left(400 \mathrm{MHz}, \mathrm{CDCl}_{3}\right)$ : $\delta 8.19\left(\mathrm{~d},{ }^{3} J=7.6 \mathrm{~Hz}, 2 \mathrm{H}\right), 7.46\left(\mathrm{t},{ }^{3} J=7.6 \mathrm{~Hz}, 2 \mathrm{H}\right), 7.38\left(\mathrm{~d},{ }^{3} J=7.2 \mathrm{~Hz}, 2 \mathrm{H}\right), 7.31\left(\mathrm{t},{ }^{3} J=7.6\right.$ 
$\mathrm{Hz}, 2 \mathrm{H}), 4.65\left(\mathrm{~d},{ }^{3} \mathrm{~J}=7.6 \mathrm{~Hz}, 4 \mathrm{H}\right), 2.09(\mathrm{~m}, 2 \mathrm{H}), 1.18-0.68(\mathrm{~m}, 60 \mathrm{H}) ;{ }^{13} \mathrm{C} \mathrm{NMR}\left(100 \mathrm{MHz}, \mathrm{CDCl}_{3}\right)$ : $\delta 157.1,147.3,147.2,138.3,137.3,136.5,136.4,134.6,134.2,133.6,133.2,129.6,128.9,126.3$, $121.2,114.2,113.4,113.3,70.9,55.7,39.1,31.8,31.5,30.6,30.5,30.4,29.7,29.4,29.2,25.7$, 25.6, 25.5, 25.5, 22.6, 22.5, 14.0, 13.9; HRMS (MALDI-TOF) calcd for $\mathrm{C}_{70} \mathrm{H}_{74} \mathrm{~N}_{8} \mathrm{~S}_{5}[\mathrm{M}]^{+}$: 1186.4634, found, 1186.4627; Anal. Calcd for $\mathrm{C}_{70} \mathrm{H}_{74} \mathrm{~N}_{8} \mathrm{~S}_{5}$ (\%): C, 70.79; H, 6.28; N, 9.43; found: C,70.48; H,6.24; N, 9.19.

Synthesis of compound F13. The synthetic processes are similar to that of F11 (61\%). ${ }^{1} \mathrm{H}$ NMR $\left(400 \mathrm{MHz}, \mathrm{CDCl}_{3}\right): \delta 8.19\left(\mathrm{dd},{ }^{3} J=8.4 \mathrm{~Hz},{ }^{4} J=4.4 \mathrm{~Hz}, 2 \mathrm{H}\right), 7.13\left(\mathrm{dd},{ }^{3} J=7.6 \mathrm{~Hz},{ }^{4} J=2.4 \mathrm{~Hz}\right.$, 2H), $6.97\left(\mathrm{td},{ }^{3} J=8.4 \mathrm{~Hz},{ }^{4} J=2.4 \mathrm{~Hz}, 2 \mathrm{H}\right), 4.66\left(\mathrm{~d},{ }^{3} J=8.0 \mathrm{~Hz}, 4 \mathrm{H}\right), 2.07(\mathrm{~m}, 2 \mathrm{H}), 1.18-0.68(\mathrm{~m}$, $60 \mathrm{H}) ;{ }^{13} \mathrm{C} \mathrm{NMR}\left(100 \mathrm{MHz}, \mathrm{CDCl}_{3}\right): \delta 167.2,164.6,156.0,147.3,145.1,139.2,139.1,137.2$, $136.4,135.7,134.2,133.9,133.8,133.6,129.5,128.0,127.9,114.5,114.3,114.0,113.4,113.1$, $110.3,110.1,71.3,55.8,39.2,31.8,31.5,30.6,30.6,30.5,30.4,29.7,29.3,29.3,29.2,25.7,25.6$, 25.5, 25.5, 22.6, 22.5, 14.0, 13.9; HRMS (MALDI-TOF) calcd for $\mathrm{C}_{70} \mathrm{H}_{72} \mathrm{~F}_{2} \mathrm{~N}_{8} \mathrm{~S}_{5}[\mathrm{M}]^{+}:$1222.4446, found, 1222.4445; Anal. Calcd for $\mathrm{C}_{70} \mathrm{H}_{72} \mathrm{~F}_{2} \mathrm{~N}_{8} \mathrm{~S}_{5}(\%)$ : C, 68.71; H, 5.93; N, 9.16; found: C, 68.70; $\mathrm{H}, 5.91 ; \mathrm{N}, 8.86$.

Solar cell fabrication. The devices were fabricated as follow: ITO/PEDOT:PSS/active layer/PDINN/Ag. ITO-coated glass substrates $\left(15 \Omega \mathrm{sq}^{-1}\right)$ were cleaned with de-ionized water, acetone, and isopropyl alcohol and then went through a 20 min oxygen plasma treatment. A rough $30 \mathrm{~nm}$ layer of PEDOT:PSS (Bayer Baytron 4083) was first spin-coated at $3000 \mathrm{rpm}$ and baked at $150{ }^{\circ} \mathrm{C}$ for 15 min under ambient conditions on the prepared ITO-coated glass substrates. The substrates were then transferred into a nitrogen-filled glovebox. After then, the active layers were spin coated from chloroform solution and then treated with thermal annealing. The donor/acceptor (D/A) weight ratio for F11:D18/F13:D18 is 1:1.4 with a total concentration is $17.6 \mathrm{mg} / \mathrm{mL}$. Then, 
PDINN was spin-coated on the active layer at $3000 \mathrm{rpm}$ from alcohol solution. Finally, silver (100 $\mathrm{nm}$ ) was thermally evaporated onto the substrates in high vacuum. The active area of the devices is $0.04 \mathrm{~cm}^{2}$ defined by shadow masks.

Device Characterization. The current density-voltage $(J-V)$ characteristics were measured using a Keithley 2400 source meter under an illumination of AM 1.5G $\left(100 \mathrm{~mW} \mathrm{~cm}^{-2}\right)$. The $J-V$ curves were measured along the forward scan direction from $0.2 \mathrm{~V}$ to $1.5 \mathrm{~V}$ or the reverse scan direction from $1.5 \mathrm{~V}$ to $0.2 \mathrm{~V}$. The illumination intensity was corrected by using a silicon photodiode with a protective KG5 filter calibrated by the National Renewable Energy Laboratory (NREL). The external quantum efficiency (EQE) was performed using certified IPCE equipment (Zolix Instruments, Inc, SolarCellScan100).

\section{SCLC Mobility Measurements.}

Space charge-limited currents were tested in hole-only devices with a structure of ITO/PEDOT:PSS/F11:D18 or F13:D18/Au and electron-only devices with a configuration of ITO/ZnO/F11:D18 or F13:D18/PFN-Br/Ag. The devices were prepared following the same procedure described in the experimental section for photovoltaic devices, except for the metal electrode. The hole and electron mobilities were calculated as follows:

$$
J=\frac{9 \varepsilon_{0} \varepsilon_{\mathrm{r}} \mu_{0} V^{2}}{8 L^{3}}
$$

Where $J$ is the current, $\mu_{0}$ is the zero-field mobility, $\varepsilon_{0}$ is the permittivity of free space, $\varepsilon_{\mathrm{r}}$ is the relative permittivity of the material, $V$ is the effective voltage, and $\mathrm{L}$ is the thickness of the active layer.

\section{Microstructure investigation.}

Atomic force microscopy (AFM) images of the thin films were obtained on a NanoscopeIIIa AFM (Digital Instruments) operating platform in tapping mode. Transmission electron microscopy 
(TEM) observation was performed on JEOL 2200FS at $160 \mathrm{kV}$ accelerating voltage. Grazing incidence X-ray diffraction characterization of the thin films was performed at the National Center for Nanoscience and Technology, China (NCNST). Thin film samples were spin-casted on to PEDOT:PSS covered $\mathrm{SiO} 2$ wafers. The scattering signal was recorded on a detector (pilatus $\mathrm{R}$ $300 \mathrm{~K})$. The detector was located at a distance of $\approx 130 \mathrm{~mm}$ from the sample.

\section{Data Availability Statement.}

The data that support the findings of this study are available from the corresponding author upon reasonable request.

\section{References}

1. Cheng, P., Li, G., Zhan, X. \& Yang, Y. Next-generation organic photovoltaics based on nonfullerene acceptors. Nat. Photon. 12, 131-142 (2018).

2. Krebs, F. C., Espinosa, N., Hosel, M., Sondergaard, R. R. \& Jorgensen, M. 25th anniversary article: rise to power — OPV-based solar parks. Adv. Mater. 26, 29-38 (2014).

3. Brabec, C. J., Heeney, M., McCulloch, I. \& Nelson, J. Influence of blend microstructure on bulk heterojunction organic photovoltaic performance. Chem. Soc. Rev. 40, 1185-99 (2011).

4. Lu, L. et al. L. Recent advances in bulk heterojunction polymer solar cells. Chem. Rev. 115, 12666-12731 (2015).

5. Yue, Q., Liu, W. \& Zhu, X. n-Type molecular photovoltaic materials: design strategies and device applications. J. Am. Chem. Soc. 142, 11613-11628 (2020).

6. Osedach, T. P., Andrew, T. L. \& Bulović, V. Effect of synthetic accessibility on the commercial viability of organic photovoltaics. Energy Environ. Sci. 6, 711-718 (2013).

7. Po, R. et al. From lab to fab: how must the polymer solar cell materials design change? — an industrial perspective. Energy Environ. Sci. 7, 925-943 (2014). 
8. Ma, L., Zhang, S., Wang, J., Xu, Y. \& Hou, J. Recent advances in non-fullerene organic solar cells: from lab to fab. Chem. Commun. 56, 14337-14352 (2020).

9. Lin, Y. et al. An electron acceptor challenging fullerenes for efficient polymer solar cells. Adv. Mater. 27, 1170-1174 (2015).

10. Jun, Y. et al. Single-junction organic solar cell with over $15 \%$ efficiency using fused-ring acceptor with electron-deficient core. Joule 3, 1140-1151 (2019).

11. Zhou, Z. et al. High-efficiency small-molecule ternary solar cells with a hierarchical morphology enabled by synergizing fullerene and non-fullerene acceptors. Nat. Energy 3, 952-959 (2018).

12. Meng, L. et al. Organic and solution-processed tandem solar cells with $17.3 \%$ efficiency. Science 361, 1094-1098 (2018).

13. Zhan, L. et al. Layer-by-layer processed ternary organic photovoltaics with efficiency over 18\%. Adv. Mater. 33, 2007231 (2021).

14. Tang, C. et al. High-performance ladder-type heteroheptacene-based nonfullerene acceptors enabled by asymmetric cores with enhanced noncovalent intramolecular interactions. Angew. Chem. Int. Ed., DOI: org/10.1002/anie.202105861 (2021).

15. Cui, Y. et al. J. Single-junction organic photovoltaic cells with approaching $18 \%$ efficiency. Adv. Mater. 32, 1908205 (2020).

16. Li, C. et al. Non-fullerene acceptors with branched side chains and improved molecular packing to exceed 18\% efficiency in organic solar cells. Nat. Energy 6, 605-613 (2021).

17. Baran, D. et al. Reducing the efficiency-stability-cost gap of organic photovoltaics with highly efficient and stable small molecule acceptor ternary solar cells. Nat. Mater. 16, 363-369 (2017). 
18. Chai, G. et al. Fine-tuning of side-chain orientations on nonfullerene acceptors enables organic solar cells with 17.7\% efficiency. Energy Environ. Sci. 14, 3469-3479 (2021).

19. Lin, F., Jiang, K., Kaminsky, W., Zhu, Z. \& Jen, A. K. A non-fullerene acceptor with enhanced intermolecular $\pi$-core interaction for high-performance organic solar cells. J. Am. Chem. Soc. 142, 15246-15251 (2020).

20. Chen, S. et al. High-performance polymer solar cells with efficiency over $18 \%$ enabled by asymmetric side chain engineering of non-fullerene acceptors. Sci. China Chem. 64, 1192-1199 (2021).

21. Gao, W. et al. Asymmetrical ladder-type donor-induced polar small molecule acceptor to promote fill factors approaching $77 \%$ for high-performance nonfullerene polymer solar cells. Adv. Mater. 30, 1800052 (2018).

22. Z. Chen et al. Small-molecular donor guest achieves rigid $18.5 \%$ and flexible $15.9 \%$ efficiency organic photovoltaic via fine-tuning microstructure morphology. Joule DOI: org/10.1016/j.joule.2021.06.017 (2021).

23. Dai, S. et al. Effect of core size on performance of fused-ring electron acceptors. Chem. Mater. 30, 5390-5396 (2018).

24. Wu, H. et al. A designed ladder-type heteroarene benzodi(thienopyran) for high-performance fullerene-free organic solar cells. Solar RRL. 1, 1700165 (2017).

25. Xiao, Z. et al. A carbon-oxygen-bridged ladder-type building block for efficient donor and acceptor materials used in organic solar cells. Sci. Bull. 62, 1331-1336 (2017);

26. Jia, S. et al. Dithieno[3,2-b:2',3'-d]pyrrol fused nonfullerene acceptors enabling over 13\% efficiency for organic solar cells. Adv. Mater. 30, 1707150 (2018);

27. Zhang, J. et al. Revealing the critical role of the HOMO alignment on maximizing current 
extraction and suppressing energy loss in organic solar cells. iScience 19, 883-893 (2019);

28. Yang, C. et al. A synergistic strategy of manipulating the number of selenophene units and dissymmetric central core of small molecular acceptors enables polymer solar cells with $17.5 \%$ efficiency. Angew. Chem. Int. Ed. 60, 19241-19252 (2021).

29. Zhang, Z. et al. Selenium heterocyclic electron acceptor with small urbach energy for as-cast high-performance organic solar cells. J. Am. Chem. Soc. 142, 18741-18745 (2020).

30. Zhao, W. et al. Molecular optimization enables over $13 \%$ efficiency in organic solar cells. $J$. Am. Chem. Soc. 139, 7148-7151 (2017).

31. Dai, S. et al. Fused nonacyclic electron acceptors for efficient polymer solar cells. J. Am. Chem. Soc. 139, 1336-1343 (2017).

32. Yang, Y. et al. Side-chain isomerization on an n-type organic semiconductor ITIC acceptor makes $11.77 \%$ high efficiency polymer solar cells. J. Am. Chem. Soc. 138, 15011-15018 (2016).

33. Liu, F. et al. Modulating structure ordering via side-chain engineering of thieno[3,4$b]$ thiophene-based electron acceptors for efficient organic solar cells with reduced energy losses. ACS Appl. Mater. Interfaces 11, 35193-35200 (2019).

34. Yang, W. et al. Balancing the efficiency, stability, and cost potential for organic solar cells via a new figure of merit. Joule 5, 1209-1230 (2021).

35. Zhou, Y. et al. High-efficiency organic solar cells based on a low-cost fully non-fused electron acceptor. Adv. Funct. Mater. 31, 2101742. (2021).

36. Li, X. et al. Simplified synthetic routes for low cost and high photovoltaic performance n-type organic semiconductor acceptors. Nat. Commun. 10, 519 (2019).

37. Li, S. et al. An unfused-core-based nonfullerene acceptor enables high-efficiency organic 
solar cells with excellent morphological stability at high temperatures. Adv. Mater. 30, 1705208 (2018).

38. Wen, T.-J. et al. Simple non-fused electron acceptors leading to efficient organic photovoltaics. Angew. Chem. Int. Ed. 60,12964-12970 (2021).

39. Chang, M. et al. Achieving an efficient and stable morphology in organic solar cells via finetuning the side Chains of small-molecule acceptors. Chem. Mater. 32, 2593-2604 (2020).

40. Zhang, X. et al. Side-chain engineering for enhancing the molecular rigidity and photovoltaic performance of noncovalently fused-ring electron acceptors. Angew. Chem. Int. Ed. 60,1772017725 (2021).

41. Hu, L. et al. Chemical reaction between an ITIC electron acceptor and an amine-containing interfacial layer in non-fullerene solar cells. J. Mater. Chem. A 6, 2273-2278 (2018);

42. Xiong, S. et al. $12.5 \%$ flexible nonfullerene solar cells by passivating the chemical interaction between the active layer and polymer interfacial layer. Adv. Mater. 31, 1806616 (2019).

43. Park, S. \& Son, H. J. Intrinsic photo-degradation and mechanism of polymer solar cells: the crucial role of non-fullerene acceptors. J. Mater. Chem. A 7, 25830-25837 (2019).

44. Guo, J. et al. Suppressing photo-oxidation of non-fullerene acceptors and their blends in organic solar cells by exploring material design and employing friendly stabilizers. J. Mater. Chem. A 7, 25088-25101 (2019).

45. Liu, H., Wang, W., Zhou, Y. \& Li, Z. A ring-locking strategy to enhance the chemical and photochemical stability of A-D-A-type nonfullerene acceptors. J. Mater. Chem. A 9, 10801088 (2020).

46. Clarke, A. J. et al. Non-fullerene acceptor photostability and its impact on organic solar cell lifetime. Cell Rep. Phys. Sci. 2, 100498 (2021). 
47. Che, Y., Niazi, M. R., Izquierdo, R. \& Perepichka, D. F. Mechanism of the Photodegradation of A-D-A Acceptors for Organic Photovoltaics. Angew. Chem. Int. Ed. 10.1002/anie.202109357 (2021).

48. Zhu, X. et al. Design of all-fused-ring electron acceptors with high thermal, chemical, and photochemical stability for organic photovoltaics. CCS Chem. 3, 1070-1080 (2021);

49. Usta, H., Facchetti, A. \& Marks, T. J. Air-stable, solution-processable n-channel and ambipolar semiconductors for thin-film transistors based on the indenofluorenebis(dicyanovinylene) core J. Am. Chem. Soc. 130, 8580-8581 (2008);

50. Che, Y. \& Perepichka, D. F. Quantifying planarity in the design of organic electronic materials. Angew. Chem. Int. Ed. 60, 1364-1373 (2021).

51. Cheng, Y.-J. et al. Thieno[3,2-b]pyrrolo donor fused with benzothiadiazolo, benzoselenadiazolo and quinoxalino acceptors: synthesis, characterization, and molecular properties. Org. Lett. 13, 5484-5487 (2011).

52. Kan, B. et al. A series of simple oligomer-like small molecules based on oligothiophenes for solution-processed solar cells with high efficiency. J. Am. Chem. Soc. 137, 3886-3893 (2015).

53. He, Z. et al. Single-junction polymer solar cells with high efficiency and photovoltage. Nat. Photon. 9, 174-179 (2015).

54. Zhao, J. et al. Efficient organic solar cells processed from hydrocarbon solvents. Nat. Energy 1, 15027 (2016).

55. Zhang, J. et al. Ring-fusion of perylene diimide acceptor enabling efficient nonfullerene organic solar cells with a small voltage loss. J. Am. Chem. Soc. 139, 16092-16095 (2017).

56. Chen, S. et al. Symmetry-induced orderly assembly achieving high-performance perylene diimide-based nonfullerene organic solar cells. CCS Chem. 3, 78-84 (2021). 
57. Lei, Z. et al. Aggregation-induced multilength scaled morphology enabling $11.76 \%$ efficiency in all-polymer solar cells using printing fabrication. Adv. Mater. 31, 1902899 (2019).

58. Hoefler, S. F. et al. The effect of polymer molecular weight on the performance of PTB7Th:O-IDTBR non-fullerene organic solar cells. J. Mater. Chem. A 6, 9506-9516 (2018).

59. Zhang, G. et al. Efficient nonfullerene polymer solar cells enabled by a novel wide bandgap small molecular acceptor. Adv. Mater. 29, 1606054 (2017).

60. Wang, X. et al. Tuning the intermolecular interaction of $A_{2}-A_{1}-D-A_{1}-A_{2}$ type non-fullerene acceptors by substituent engineering for organic solar cells with ultrahigh $V_{\mathrm{OC}}$ of $\sim 1.2 \mathrm{~V}$. Sci. China Chem. 63, 1666-1674 (2020).

61. Mercier, L. G. \& Leclerc, M. Direct (hetero)arylation: a new tool for polymer chemists. Acc. Chem. Res. 46, 1597-1605 (2013).

62. Luke, J. et al. Twist and degrade-impact of molecular structure on the photostability of nonfullerene acceptors and their photovoltaic blends. Adv. Energy Mater. 9, 1803755 (2019).

63. Na, S.-I. et al. High performance roll-to-roll produced fullerene-free organic photovoltaic devices via temperature-controlled slot die coating. Adv. Funct. Mater. 29, 1805825 (2018).

64. Ye, L. et al. Surpassing 10\% efficiency benchmark for nonfullerene organic solar cells by scalable coating in air from single nonhalogenated solvent. Adv. Mater. 30, 1705485 (2018).

65. Sun, K. et al. The role of solvent vapor annealing in highly efficient air-processed small molecule solar cells. J. Mater. Chem. A 2, 9048-9054 (2014).

66. Wu, H. et al. Conjugation-curtailing of benzodithionopyran-cored molecular acceptor enables efficient air-processed small molecule solar cells. Small 15, 1902656 (2019).

67. Holliday, S. et al. High-efficiency and air-stable P3HT-based polymer solar cells with a new non-fullerene acceptor. Nat. Commun. 7, 11585 (2016). 
68. Drakonakis, V. M., Savva, A., Kokonou, M. \& Choulis, S. A. Investigating electrodes degradation in organic photovoltaics through reverse engineering under accelerated humidity lifetime conditions. Sol. Energy Mater. Sol. Cells 130, 544-550 (2014).

69. Mateker, W. R. \& McGehee, M. D. Progress in understanding degradation mechanisms and improving stability in organic photovoltaics. Adv. Mater. 29, 1603940 (2017). 


\section{Acknowledgements}

The authors thank the National Key R\&D Program of China (2019YFA0705900, 2017YFA0204701), the National Natural Science Foundation of China $(22175187,91833304$ and 21805289) and the Youth Innovation Promotion Association CAS (2020031) for their financial support.

\section{Author contributions}

Z. X. conceived and directed the project. L.W. performed the stability tests and device fabrication and characterization. X. S. synthesized F11 and F13. All authors discussed the results and substantially contributed to the preparation of the manuscript.

\section{Additional information}

Supplementary information is available in the online version of the paper. Reprints and permission information are available online at www.nature.com/reprints. Correspondence and requests for materials should be addressed to X.Z.

\section{Competing interests}

The authors declare no competing interests. 
Figures and figure captions

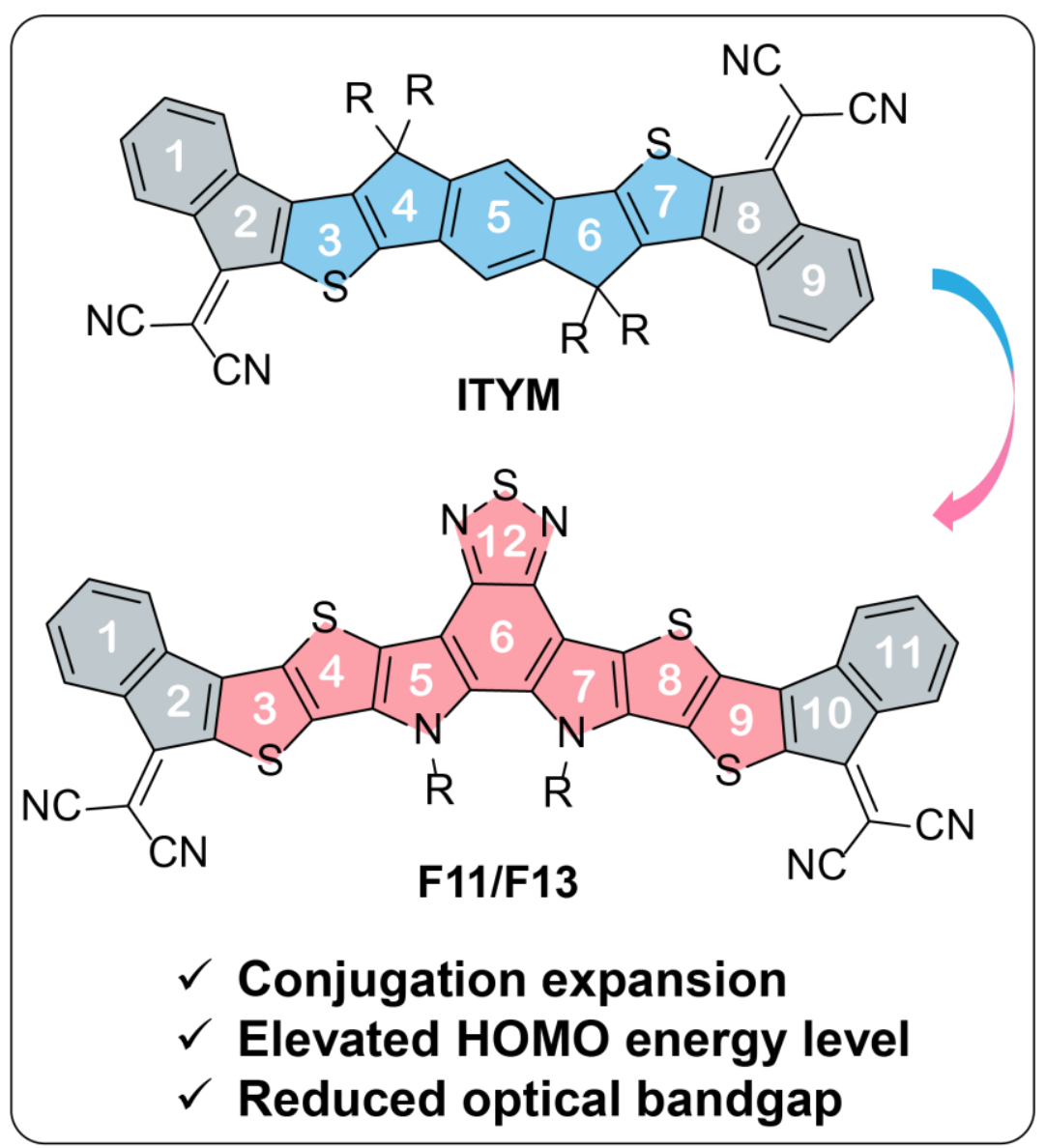

Fig. 1 | Design of dodecacyclic AFRAs, F11/F13. 


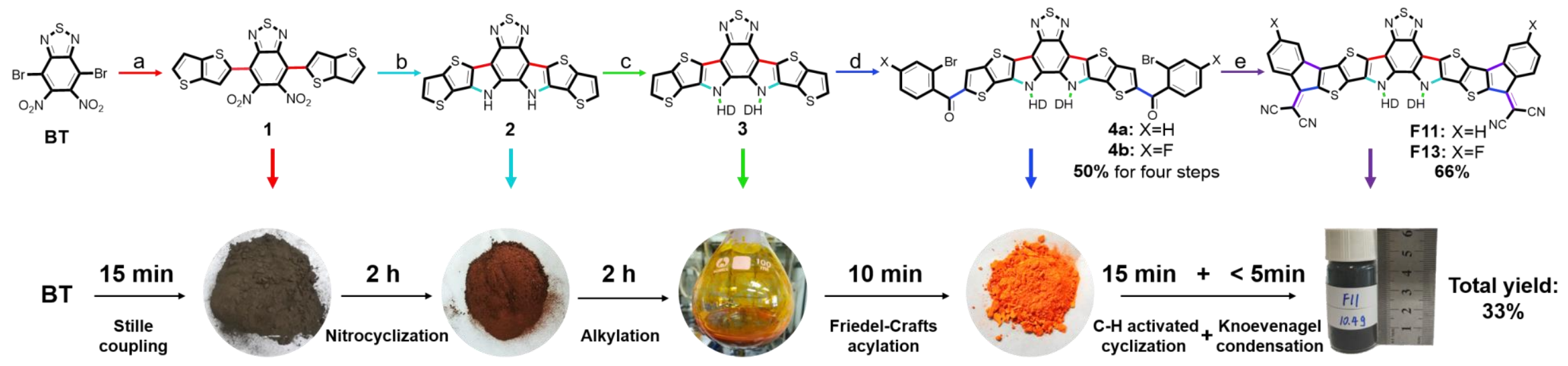

Fig. 2 Quick large-scale preparation of the all-fused-ring acceptors, F11 and F13. a, $\mathrm{Pd}_{2}(\mathrm{dba})_{3}, \mathrm{P}(o-\text { tol })_{3}$, tributyl(thieno[3,2- $\left.b\right]$ thiophen-2yl)stannane, toluene. b, $\mathrm{PPh}_{3}$, o-dichlorobenzene. c, $\mathrm{HD}-\mathrm{Br}_{2} \mathrm{~K}_{2} \mathrm{CO}_{3}, N, N$-dimethylformamide, $\mathrm{HD}$ = 2-hexyldecanyl. d, $\mathrm{AlCl}_{3}$, o-bromoaryl chloride, dichloromethane. e, $1 . \mathrm{K}_{2} \mathrm{CO}_{3}, N, N$-dimethylacetamide, $\mathrm{Pd}(\mathrm{OAc})_{2}, \mathrm{PH}(\text { cyc-hex })_{3} \cdot \mathrm{BF}_{4} ; 2$. Malononitrile, TiCl 4 , pyridine, chlorobenzene. 
a

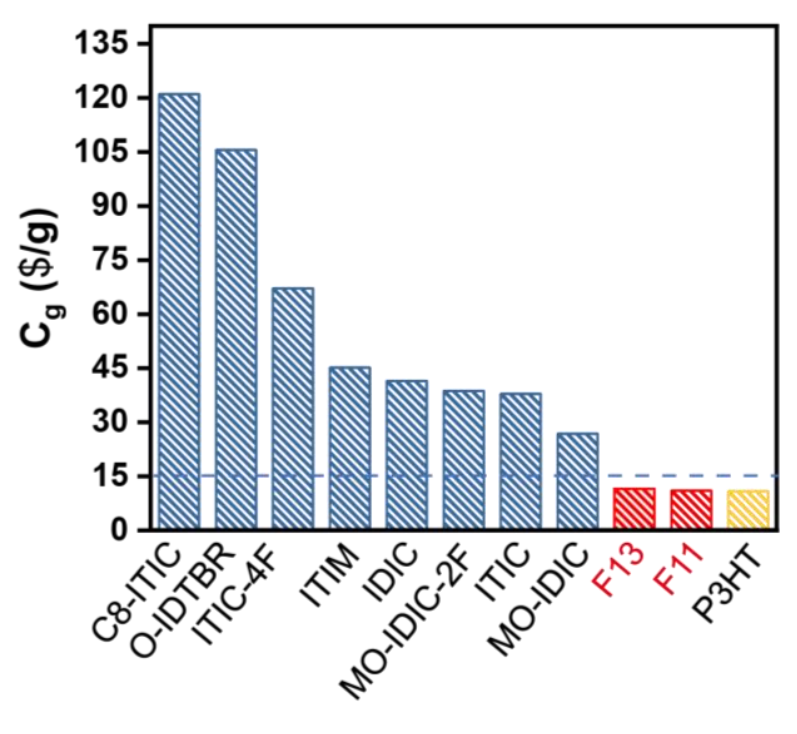

b

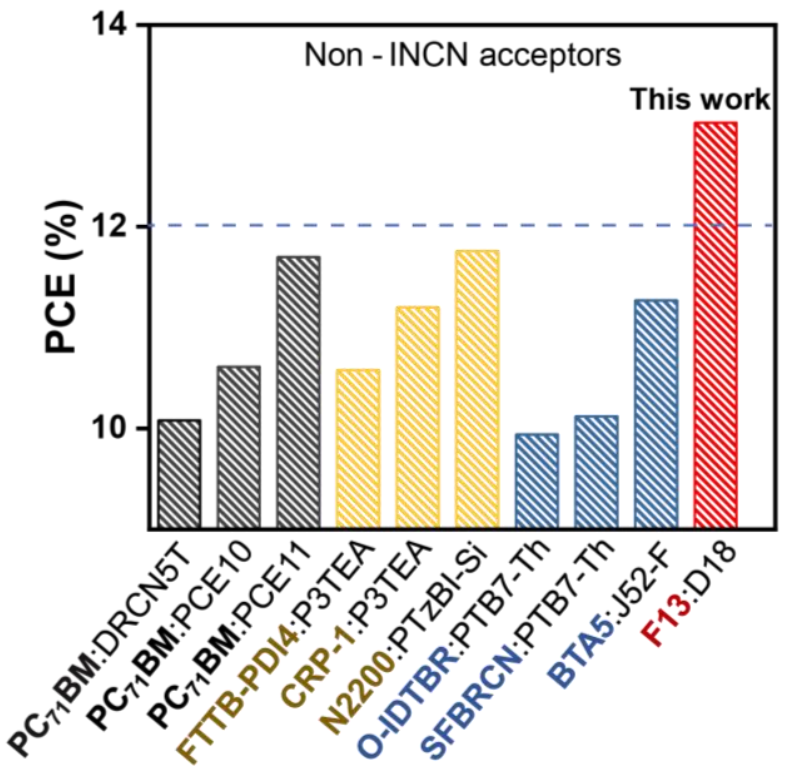

Fig. 3 Statistics of costs and PCEs. a, Histogram of material costs $C g(\$ / g)$ for the different photovoltaic materials (material costs are adopted from the reference, ${ }^{[36]}$ except for our acceptors). b, Statistics of high PCEs for typical non-INCN series photovoltaic acceptors (Supplementary Table 3). 
a

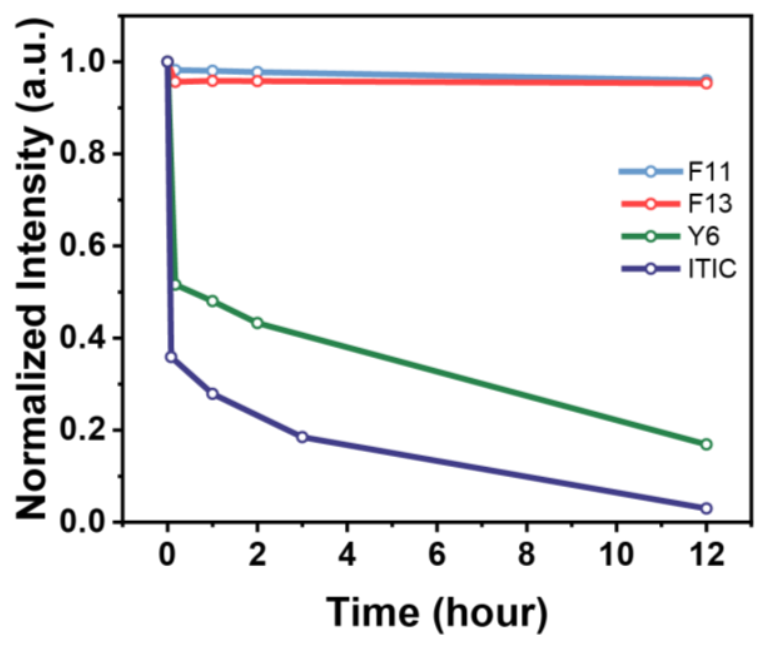

b

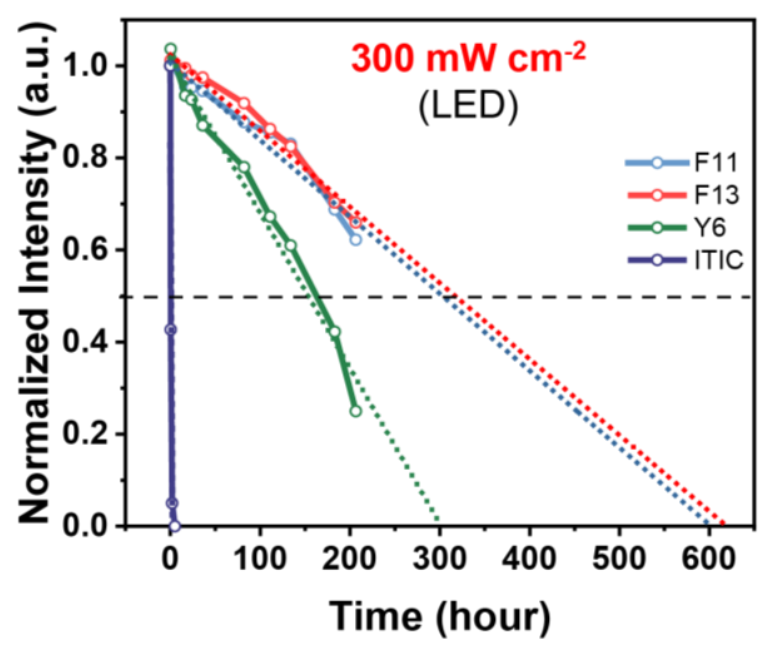

Fig. 4 Stabilities of four NFA acceptors. The time-dependent absorption decays of acceptors at the corresponding maximum absorptions upon a, the EA treatment in THF: $\mathrm{H}_{2} \mathrm{O}$ mixtures $(96: 4$, $\mathrm{v} / \mathrm{v}$ ) (the concentration of NFAs is controlled at $10^{-5} \mathrm{M}$, while that of EA is $10^{-3} \mathrm{M}$ ) and $\mathbf{b}, 300$ $\mathrm{mW} \mathrm{cm}^{-2}$ (LED) irradiation in films. 
a
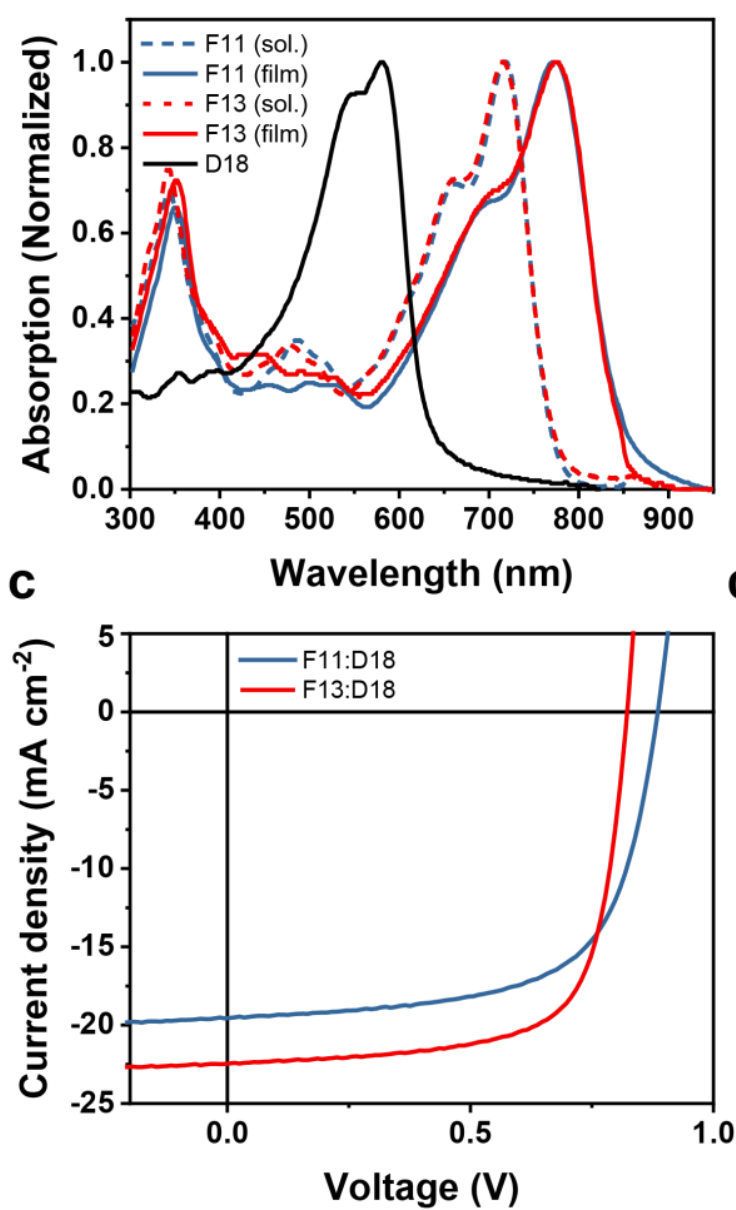

b
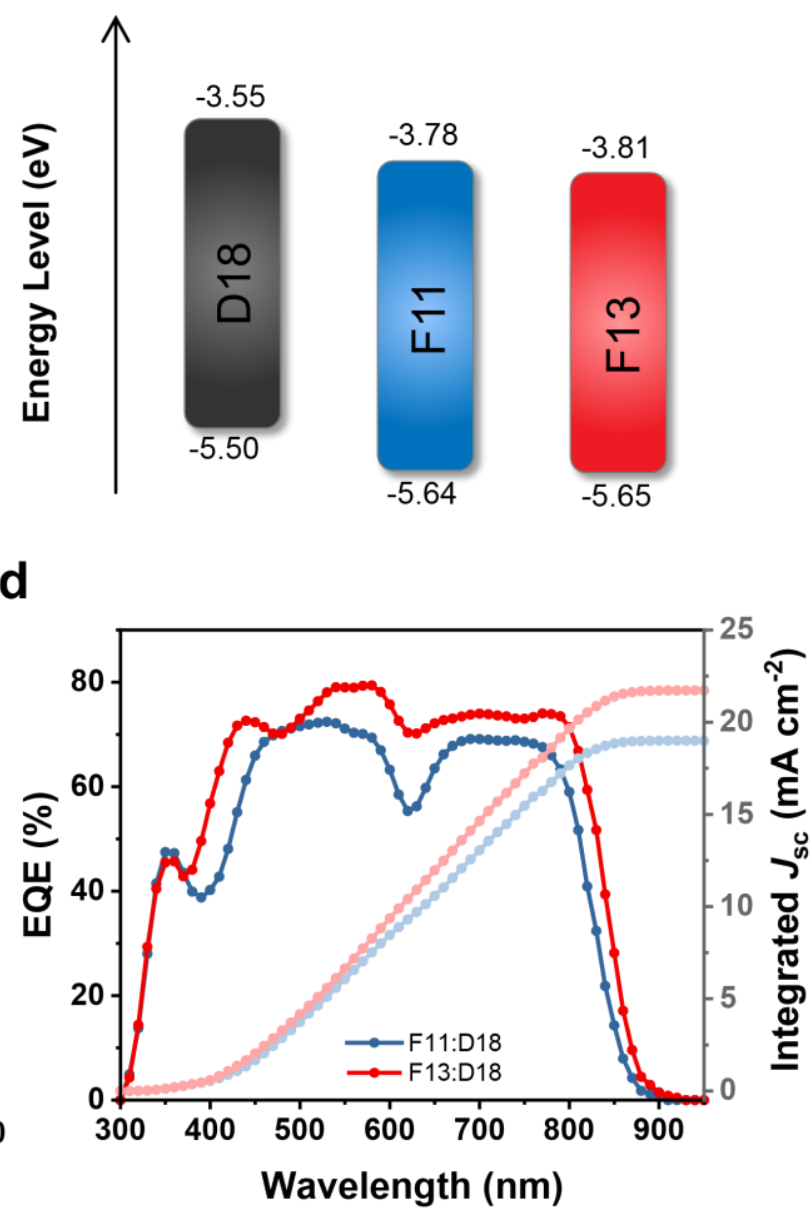

Fig 5 | Photovoltaic performance of F11/F13:D18-based OSCs. a, Normalized UV-vis-NIR absorption spectra. b, Energy diagram of D18, F11 and F13. c, $J-V$ and d, EQE curves for OSCs based on F11:D18 and F13:D18 under AM 1.5G irradiation $\left(100 \mathrm{~mW} \mathrm{~cm}^{-2}\right)$. 
a

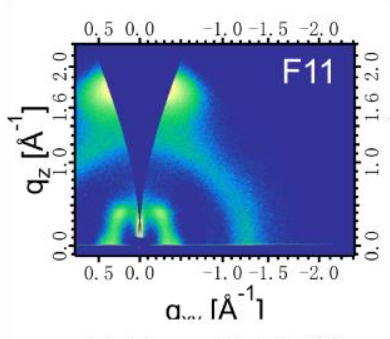

a... $\left\lceil\AA^{-1}\right]$

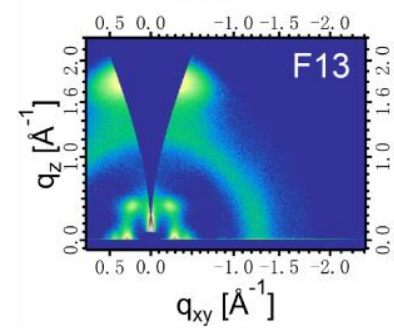

b
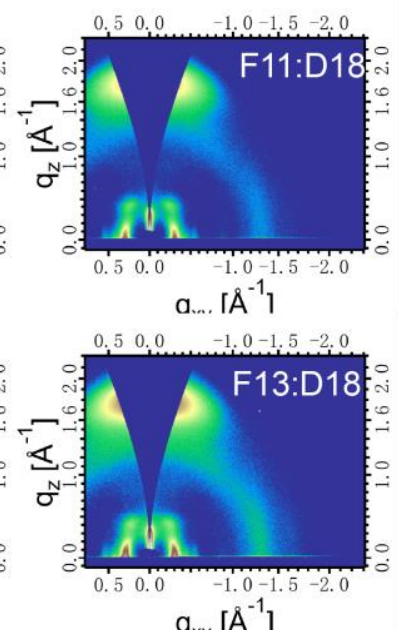

C

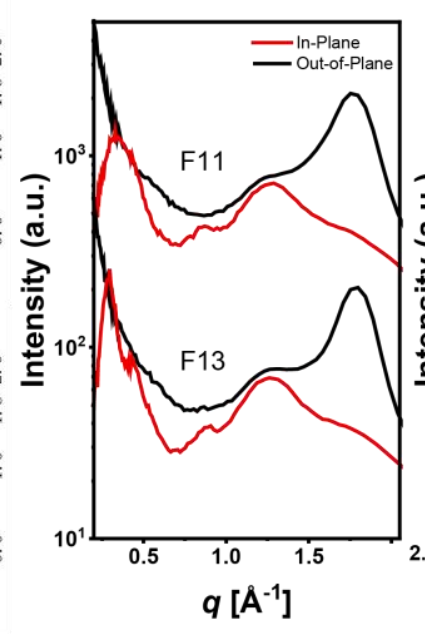

d

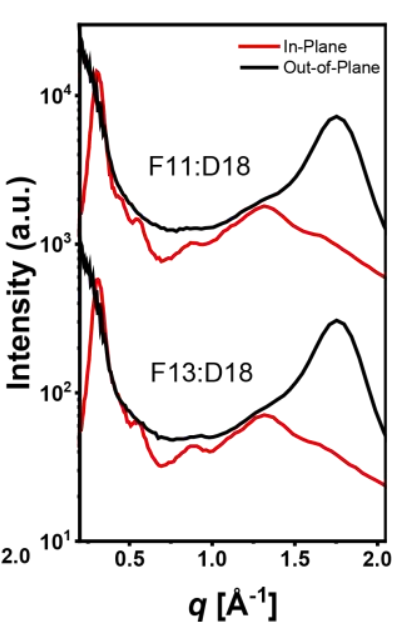

Fig. 6 | GIWAXS patterns of F11/F13-based active layers. 2D GIWAXS patterns of a, pristine films and $\mathbf{b}$, blend films. GIWAXS intensity profiles along the in-plane and out-of-plane directions of c, pristine films and d, blend films. 

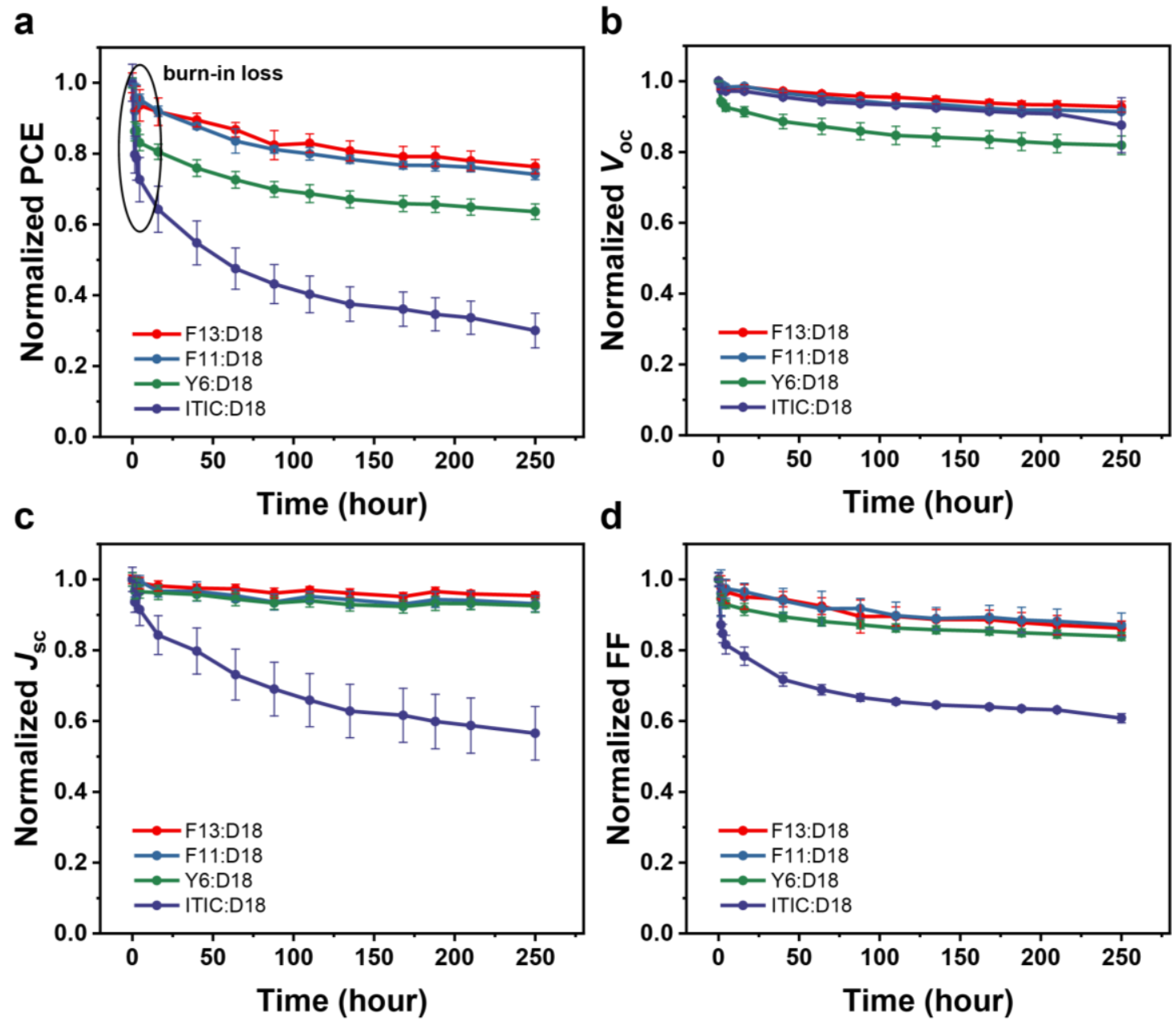

Fig. $7 \mid$ OSC device stability. Evolution of a, PCE, b, $V_{\text {oc }}, \mathbf{c}, J_{\mathrm{sc}}$ and d, FF of devices based on air-processed active layers. These devices with structure of ITO/PEDOT:PSS/active layer/PDINN/Ag, were placed in a glovebox filled with dry nitrogen atmosphere under continuous irradiation (LED, $100 \mathrm{~mW} \mathrm{~cm}^{-2}$, an average of six devices). 
Table 1. Photovoltaic parameters of F11/F13-based OSCs under the illumination of AM 1.5G, $100 \mathrm{~mW} \mathrm{~cm}^{-2}$.

\begin{tabular}{|c|c|c|c|c|c|c|c|c|}
\hline Acceptors & $\begin{array}{l}V_{\text {oc }} \\
(\mathrm{V})\end{array}$ & $\begin{array}{c}\boldsymbol{J}_{\mathbf{s c}} \\
\left(\mathrm{mA} \mathrm{cm}^{-2}\right)\end{array}$ & $\begin{array}{c}\boldsymbol{J}_{\text {cal }} \\
\left(\mathrm{mA} \mathrm{cm}^{-2}\right)\end{array}$ & $\begin{array}{l}\text { FF } \\
(\%)\end{array}$ & $\begin{array}{c}\text { PCE } \\
(\%)\end{array}$ & $\begin{array}{c}\boldsymbol{\mu} \mathbf{h} \\
\left(\times 10^{-4} \mathrm{~cm}^{2} \mathrm{~V}^{-1} \mathrm{~s}^{-1}\right)\end{array}$ & $\begin{array}{c}\boldsymbol{\mu} \mathbf{e} \\
\left(\times 10^{-4} \mathrm{~cm}^{2} \mathrm{~V}^{-1} \mathrm{~s}^{-1}\right)\end{array}$ & $\mu \mathrm{e} / \mu \mathrm{h}$ \\
\hline F11 & $\begin{array}{c}0.886 \\
(0.885 \pm 0.005)\end{array}$ & $\begin{array}{c}19.53 \\
(19.15 \pm 0.68)\end{array}$ & 18.99 & $\begin{array}{c}64.78 \\
(65.08 \pm 0.01)\end{array}$ & $\begin{array}{c}11.20 \\
(11.03 \pm 0.28)\end{array}$ & 1.70 & 3.75 & 2.2 \\
\hline F13 & $\begin{array}{c}0.822 \\
(0.822 \pm 0.004)\end{array}$ & $\begin{array}{c}22.46 \\
(22.26 \pm 0.14)\end{array}$ & 21.72 & $\begin{array}{c}70.41 \\
(70.13 \pm 0.34)\end{array}$ & $\begin{array}{c}13.01 \\
(12.84 \pm 0.07)\end{array}$ & 4.04 & 6.45 & 1.6 \\
\hline
\end{tabular}

The average values with standard deviations were obtained from more than 10 individual devices. 